\title{
LA CORTE SUPREMA DE JUSTICIA Y LA DEFENSA DE LA PROPIEDAD PRIVADA BAJO EL ESTADO DE SITIO EN TIEMPOS DE LA CONSTITUCIÓN DE 1886*
}

\author{
THE SUPREME COURT AND THE \\ DEFENSE OF PRIVATE PROPERTY UNDER \\ THE STATE OF SIEGE IN THE TIMES \\ OF THE CONSTITUTION OF 1886
}

\author{
Mario Alberto Cajas-Sarria** \\ Fecha de recepción: 5 de octubre de 2016 \\ Fecha de aceptación: 24 de octubre de 2016 \\ Disponible en linea: 30 de mayo de 2017
}

\section{Para citar este artículo/To cite this article}

Cajas-Sarria, Mario Alberto, La Corte Suprema de Justicia y la defensa de la propiedad privada bajo el estado de sitio en tiempos de la Constitución de 1886, 134 Vniversitas, 93-138 (2017). http://dx.doi.org/10.11144/ Javeriana.vj134.csjd doi:10.11144/Javeriana.vj134.csjd

Este artículo es un producto de investigación desarrollado por el autor en el grupo de investigación Precedente, Facultad de Derecho y Ciencias Sociales, Universidad Icesi, Cali.

** Profesor asociado y jefe del Departamento de Estudios Jurídicos, Facultad de Derecho y Ciencias Sociales, Universidad Icesi, Cali. Abogado, Universidad del Cauca. Especialista en derecho público, Universidad Externado de Colombia. Magíster en derecho, Universidad Nacional de Colombia. Doctor en derecho, Universidad de los Andes. Contacto: mcajas@icesi.edu.co 


\section{RESUMEN}

Este artículo de investigación examina dos sentencias de la Corte Suprema de Justicia de Colombia, como juez constitucional, bajo la Constitución Nacional de 1886, que defendieron el derecho a la propiedad privada frente a expropiaciones ordenadas por decretos de estado de sitio dictados por el presidente de la república, aun cuando en ambos fallos la corporación evitó pronunciarse sobre los límites del poder Ejecutivo bajo el estado de excepción. Así, a través de una historia política del control constitucional se pone en evidencia el comportamiento estratégico de la Corte Suprema en dos momentos determinados: el primero en su etapa inaugural como juez constitucional en 1912 y el segundo, bajo el régimen militar del general Gustavo Rojas Pinilla en 1954. Estos dos fallos sirven para mostrar el rol político de la Corte Suprema de Justicia, y la interdependencia entre la política y el derecho en la construcción de la defensa judicial de la Constitución en Colombia.

Palabras clave: Propiedad privada; estado de sitio; Constitución de 1886; control constitucional del estado de sitio 


\section{ABSTRACT}

This research article analyzes two decisions of the Supreme Court of Colombia, as a constitutional tribunal under the Constitution of 1886, where it defended the right to private property against expropriations ordered by decrees of state of siege enacted by the President of the Republic; although, in these decisions it avoided ruling on the limits of the executive branch under the state of siege. Thus, by means of a political history of judicial review, this article explains the strategic behavior of the Court in two different stages: the first, in its inaugural moment as a constitutional tribunal in 1912, and the second, under the military rule of General Gustavo Rojas Pinilla in 1954. Those decisions show the political role of the Court, and the interdependence between politics and law in the construction of the judicial review in Colombia.

Keywords: right to private property; state of siege; constitution of 1886; judicial review of the state of siege

\section{SUMARIO}

Introducción.- I. La Corte Suprema de Justicia y la defensa de la PROPIEDAD PRIVADA: 1912.- A. Del gobierno del general Reyes a la reforma constitucional de 1910.- B. La propiedad en la Constitución: 1886-1910.C. La sentencia del 11 de noviembre de 1912.- II. La CoRTe Suprema y LA DEFENSA DE LA PROPIEDAD PRIVADA BAJO EL ESTADO DE SITIO: 1954.- $A$. La propiedad privada en la Constitución: 1936 a 1954.- B. El golpe de Estado del general Rojas Pinilla y la Corte de 1954.- C. La Corte Suprema y Los límites a la propiedad fijados por medidas de estado de sitio: 1954.- REFLEXIONES FINALES.- BIBLIOGRAFÍA. 


\section{INTRODUCCIÓN}

Uno de los fenómenos más complejos y analizados por la literatura jurídica y política colombiana es el uso recurrente de los estados de excepción por parte del poder Ejecutivo, en particular del estado de sitio bajo la Constitución Nacional de 1886. A este régimen se le acusa de propiciar la vulneración de derechos humanos, en especial a partir de la década de los setenta del siglo XX; y en buena medida, tal crítica fundamentó el discurso político y legal que condujo a la expedición de la Constitución Política de 1991.

La Constitución de 1886 dotaba al presidente de la república de tan amplias facultades bajo el régimen de estado de sitio, que incluso podía derogar las leyes dictadas por el Congreso cuando considerase que aquellas eran incompatibles con el estado de excepción ${ }^{2}$. Para declarar el estado de sitio bastaba con que el presidente dictase un decreto firmado por todos sus ministros y luego, con base en esa declaratoria, se expedían los decretos legislativos correspondientes. El Acto legislativo 03 de $1910^{3}$ intentó fijar límites a ese enorme poder presidencial al determinar que en adelante el presidente solo podría "suspender" las leyes contrarias al estado de sitio.

1 Uno de los trabajos que mejor ilustran las críticas a la Constitución de 1886 a finales del siglo XX es: Hernando Valencia-Villa, Cartas de batalla: una crítica del constitucionalismo colombiano (Universidad Nacional de Colombia, CEREC, Bogotá, 1987).

2 La Constitución de 1886 dio forma jurídica a los proyectos políticos e ideológicos que convergían en la Regeneración, que condujo el presidente Rafael Núñez [mandatos presidenciales 8 de abril de 1880-1 de abril de 1882, 11 de agosto de 1884-1 de abril de 1886, 4 de abril de 1887-7 de agosto de 1892, 29 de septiembre de 1892-18 de septiembre de 1894] con la agencia del conservador Carlos Holguín-Mallarino [mandato presidencial 7 de agosto de 1888-7 de agosto de 1892] y el dogmatismo ultraconservador y católico de Miguel Antonio Caro [mandato presidencial 7 de agosto de 1892-7 de agosto de 1898]. La Carta tenía un fuerte tinte autoritario, se definía por la centralización política y administrativa del Estado y por la concentración del poder en el Ejecutivo. Colombia, Constitución Política de 1886, 5 de agosto de 1886. Sobre la Regeneración y la Constitución de 1886: Antonio BARRETO-Rozo, Venturas y desventuras de la Regeneración: apuntes de historia jurídica sobre el proyecto politico de 1886 y sus transformaciones y rupturas en el siglo XX (Universidad de los Andes, Bogotá, 2011). Miguel Malagón-Pinzón, La Regeneración, la Constitución de 1886 y el papel de la Iglesia Católica, 11 Civilizar, Ciencias Sociales y Humanas (2006). Disponible en: http:// repository.usergioarboleda.edu.co/bitstream/handle/11232/336/CienciasSocialesyHumanas6117. pdf?sequence $=1$. Jorge Orlando Melo, Núñez y la Constitución de 1886: triunfo y fracaso de un reformador, en Núnez y Caro 1886 (Banco de la República, Bogotá, 1986). Jorge Orlando Melo, La Constitución de 1886, en Nueva Historia de Colombia, Tomo 1, Historia Política 1886-1946, 43-64 (Álvvaro Tirado-Mejía, ed., Planeta, Bogotá, 1989). Charles W. Bergquist, Café y conflicto en Colombia, 1886-1910: la guerra de los Mil Días: sus antecedentes y consecuencias (Fundación Antioqueña de Estudios Sociales, FAES, Medellín, 1981).

3 Colombia, Acto legislativo 03 de 1910, reformatorio de la Constitución Nacional, 31 de octubre de 1910, 14131 Diario Oficial, 31 de octubre de 1910. Disponible en: http://suin-juriscol.gov.co/ viewDocument.asp?id=1825559 
La misma reforma constitucional de 1910 estableció la acción pública de inconstitucionalidad, que facultó a cualquier ciudadano para demandar directamente ante la Corte Suprema de Justicia aquellos decretos y leyes que considerara contrarios a la Constitución. Este singular mecanismo de defensa judicial de la Constitución, por cierto, antecede al sistema de control constitucional concentrado de tipo austriaco o europeo continental, al tiempo que es posterior al control difuso o Judicial Review estadounidense, sin que este fenómeno haya sido analizado adecuadamente por la literatura jurídica global o la historia constitucional comparada ${ }^{4}$.

Aunque el control constitucional en Colombia es de vieja data, la escasez de estudios sobre la justicia constitucional en perspectiva histórica y la carencia de trabajos en torno al papel de la Corte Suprema de Justicia como juez constitucional del estado de sitio resultan fuertemente contrastantes. En efecto, ni la academia jurídica ni la academia política se han ocupado de estudiar el papel político de los jueces constitucionales en una perspectiva histórica: los juristas suelen analizar estos tribunales enfocándose en una doctrina aislada del contexto político; y la ciencia política suele estudiar la justicia constitucional desde la "política judicial", de modo que por lo general ambas les dan poca importancia a las doctrinas legales o a la perspectiva histórica de la justicia constitucional ${ }^{6}$.

4 Sobre los orígenes de la acción pública de inconstitucionalidad y la defensa judicial de la constitución por la Corte Suprema, Mario Alberto Cajas-Sarria, La Corte Suprema de Justicia de Colombia, 1886-1910: de juez de la Regeneración a juez constitucional, 14 Historia Constitucional, 425-465 (2013). Disponible en: http://www.historiaconstitucional.com/index.php/historiaconstitucional/ article/view/378/341. Andrés Botero-Bernal analiza la singularidad del caso colombiano: ANDRÉs Botero-Bernal, Haciendo memoria de la defensa judicial de la Constitución, 20 Pensamiento Jurídico, 91-102 (2007). Disponible en: http://www.revistas.unal.edu.co/index.php/peju/article/ view/38627/pdf_239

5 Entre los estudios sobre el estado de sitio se destacan: Jorge GonZÁlez-Jácome, Estados de excepción y democracia liberal en América del Sur: Argentina, Chile y Colombia, 1930-1990 (Pontificia Universidad Javeriana, Bogotá, 2015). AnTONIO BARRETo-Rozo, La generación del estado de sitio, el juicio de anormalidad institucional de la Asamblea Nacional Constituyente de 1991 (Universidad de los Andes, Bogotá, 2012). Manuel IturRalde, Castigo, liberalismo autoritario y justicia penal de excepción (Siglo del Hombre Editores, Bogotá, 2009). Mauricio García-Villegas, Constitucionalismo perverso, normalidad y anormalidad constitucionalidad en Colombia, 1957-1997, en El caleidoscopio de las justicias en Colombia: análisis socio-jurídico, Tomo I, 317-370 (BOAventura de Sousa-Santos \& Mauricio García-Villegas, eds., Colciencias, Instituto Colombiano de Antropología e Historia, ICANH, Universidad de los Andes, Siglo del Hombre, Bogotá, 2001). Gustavo Gallón-Giraldo, Quince años de estado de sitio en Colombia, 1958-1978 (Ediciones Guadalupe, Bogotá, 1979).

6 Para un mapa del control constitucional en una perspectiva histórica y política: MARIO ALBERTO CAJas-Sarria, La historia de la Corte Suprema de Justicia de Colombia, 1886-1991, Tomos I y II (Universidad de los Andes, Universidad Icesi, Bogotá, 2015). 
En cuanto al control constitucional del estado de sitio, la escasa literatura académica que lo aborda de algún modo, bien sea al examinar algunas sentencias o períodos del tribunal, de ordinario afirma que la Corte Suprema de Justicia fue laxa, deferente y hasta evasiva para juzgar la constitucionalidad de la legislación de excepción. Además, que fue muy pasiva para proteger los derechos humanos ante las duras medidas dictadas bajo estado de sitio; como aquellas que sometían a los civiles a la justicia penal militar y que por regla general la Corte convalidó hasta $1987^{7}$, cuando declaró inconstitucional un decreto que le asignaba a la justicia penal militar la competencia para investigar y juzgar a civiles por delitos de narcotráfico, en plena guerra contra las drogas ${ }^{8}$.

Este artículo examina dos momentos distintos de la historia política colombiana a partir de los cuales la Corte Suprema de Justicia defendió el derecho a la propiedad privada y los derechos adquiridos bajo el régimen de estado de sitio, en tiempos de la Constitución de 1886. Ambos se refieren a medidas del ejecutivo que ordenaron expropiaciones y que la Corte declaró inconstitucionales. El primero se sitúa en 1912 en los comienzos del control constitucional atribuido a la Corte por la reforma constitucional de 1910, cuando el tribunal conoció una demanda en contra de un decreto dictado por el recién depuesto gobierno dictatorial del general Rafael Reyes [7 de agosto de 1904-27 de julio de 1909]. El segundo se ubica en 1954, en el régimen militar del general Gustavo Rojas Pinilla [13 de junio de 1953-10 de mayo de 1957], cuando la Corte declaró inconstitucional un decreto dictado en 1952 por el gobierno del presidente conservador Laureano Gómez.

Los dos episodios que se narran permiten apreciar cómo la Corte protegió la propiedad privada, como derecho fundante del Constitucionalismo y del Estado Liberal, incluso bajo estados de excepción ${ }^{9}$. Al mismo tiempo, ponen en evidencia que la Corte esta

7 Colombia, Corte Suprema de Justicia, Sentencia 20, 5 de marzo de 1987, magistrado ponente Jesús Vallejo-Mejía, 2340 Gaceta Judicial, 212-224, enero a junio de 1987.

8 Un estudio del comportamiento de la Corte como juez constitucional del estado de sitio en: MARIO Alberto Cajas-SARria, La historia de la Corte Suprema de Justicia de Colombia, 1886-1991, Tomos I y II (Universidad de los Andes, Universidad Icesi, Bogotá, 2015).

9 La bibliografía sobre las relaciones entre la propiedad privada, el Constitucionalismo Liberal y el Estado Liberal Clásico es abundante. Uno de los más influyentes en el ideario constitucional es: JoHN Locke, Segundo Tratado sobre el gobierno civil: un ensayo acerca del verdadero origen, alcance y fin del Gobierno Civil (Carlos Mellizo, traducción, prólogo y notas, Alianza, Madrid, 1990). 
defensa la hizo evitando al máximo inmiscuirse en el debate sobre los límites al poder presidencial bajo el estado de sitio. La corporación, pues, actuó de manera estratégica para tratar de quedar al margen de las disputas políticas con el poder Ejecutivo, aunque paralelamente quiso garantizar la propiedad como piedra angular del Constitucionalismo Liberal. De este modo, este artículo permite apreciar cómo la Corte hizo prevalecer el derecho a la propiedad privada, incluso en tiempos de regímenes autoritarios como los de las dictaduras de los generales Rafael Reyes y Gustavo Rojas Pinilla, en dos momentos bien diferenciados de la historia política colombiana.

Esta aproximación a la historia del derecho judicial colombiano pretende contribuir a la comprensión del papel que jugó la Corte Suprema de Justicia en la defensa de los derechos bajo la vigencia de la Constitución de $1886^{10}$. En este caso, de cómo la justicia constitucional defendió el derecho a la propiedad privada, incluso en estados de excepción. Desde luego, con esto no se busca hacer una apología de la jurisprudencia de la Corte ni tampoco ocultar su déficit garantista en el control constitucional del estado de sitio, sino explorar nuevas miradas a un campo cuyo foco se ha situado en la vulneración de derechos civiles y políticos bajo el estado de excepción durante buena parte del siglo XX.

Este artículo hace parte de una agenda de investigación que busca reconstruir la trayectoria de la justicia constitucional colombiana con una perspectiva más amplia que aquellas que predominan en la literatura jurídica, politológica e historiográfica local ${ }^{11}$. En esta

José LuIS DE Los Mozos, El derecho de propiedad: crisis y retorno a la tradición jurídica (Editorial Revista de Derecho Privado, Editoriales de Derecho Reunidas, Madrid, 1993). Para un análisis de la construcción del concepto de propiedad y del derecho privado en Estados Unidos: MorTon J. Horwitz, The Transformation of American Law, 1870-1960: The Crisis of Legal Orthodoxy (Oxford University Press, Oxford, 1992). Sobre la relación entre propiedad, igualitarismo y liberalismo en el contexto latinoamericano: RoBerto GARGARELla, Los fundamentos legales de la desigualdad: el constitucionalismo en América (1776-1860) (Siglo XXI, Buenos Aires, 2010). En el caso colombiano fue muy influyente la concepción de la propiedad privada del Código Civil de: Fernando VéLEz, Estudio sobre el Derecho Civil colombiano (Imprenta Nacional, Medellín, 1909).

10 Una interpretación historiográfica y desmitificadora de la Regeneración y de la Constitución de 1886 en: Bernd Marquardt, Estado y Constitución en la Colombia de la Regeneración del Partido Nacional, 1886-1909, 6 Ciencia Política, 11, 56-81 (2011). Disponible en: http://www.revistas.unal. edu.co/index.php/cienciapol/article/view/41501/43115

11 La propuesta para construir una narrativa de la historia de la Corte Suprema de Justicia de Colombia en una perspectiva política se desarrolla en el primer capítulo de: MARIO AlBERTo CAJAS-SARria, $L a$ historia de la Corte Suprema de Justicia de Colombia, 1886-1991, Tomo I, De la Regeneración al régimen militar, 1886-1958, 13-54 (Universidad de los Andes y Universidad Icesi, Bogotá, 2015). 
narrativa, el cambio constitucional no se explica como el producto de la evolución - o involución - de las doctrinas legales de la Corte o del derecho nacional ${ }^{12}$, ni como el resultado único de las condiciones políticas en que estuvo inmerso el tribunal; tampoco como consecuencia de las ideologías de sus magistrados; o de las estrategias políticas de cada uno de ellos; o de la corporación en su conjunto frente a otras instituciones, en una determinada decisión ${ }^{13}$.

Desde esta perspectiva, la Corte Suprema de Justicia se concibe como un órgano judicial que decidió casos en determinados contextos y coyunturas políticas, que actuó bajo un ambiente institucional interno (los magistrados, sus estrategias) y externo (las presiones de las otras ramas del poder, las audiencias: partidos y opinión pública); es decir, fue juez y a la vez un actor político, pero un actor político "especial", que no se puede comparar con el Legislativo o el Ejecutivo pues a diferencia de esos órganos elegidos democráticamente, la legitimidad del tribunal descansaba en su jurisprudencia, en sentencias que debían expresar el ideal de un ejercicio apolítico y neutral del Derecho. Como operador jurídico, actuó sometida a las restricciones del sistema jurídico, del discurso legal y a las que su pertenencia a una comunidad interpretativa de juristas le imponían ${ }^{14}$.

El artículo tiene la siguiente estructura. Comienza con una contextualización de los inicios del siglo XX colombiano, que enmarca el gobierno del general Rafael Reyes y la creación de la acción pública de inconstitucionalidad. Luego se aproxima de modo general al surgimiento del control constitucional por vía de acción ciudadana que se atribuyó a la Corte Suprema de Justicia en la reforma constitucional de 1910. Después examina con detalle los dos momentos en la historia política colombiana en que el tribunal defendió el derecho a la propiedad privada frente a medidas de estado de sitio: 1912 y 1954. Al cierre se ofrecen unas reflexiones finales.

12 Reconociendo, por supuesto, las interdependencias entre las doctrinas locales y las globales, así como la historia de las conexiones conceptuales entre distintos circuitos intelectuales del pensamiento jurídico.

13 Ronald Kahn \& Ken I. Kersch, eds., The Supreme Court and American Political Development, 1-32 (University Press of Kansas, Lawrence, Kansas, 2006).

14 Ronald Kahn \& Ken I. Kersch, eds., The Supreme Court and American Political Development, 1-32 (University Press of Kansas, Lawrence, Kansas, 2006). 


\section{LA CORTE SUPREMA DE JUSTICIA Y LA DEFENSA DE LA PROPIEDAD PRIVADA: 1912}

\section{A. Del gobierno del general Reyes a la reforma constitucional de 1910}

Colombia padeció la cruenta Guerra de los Mil Días entre el 17 de octubre de 1899 y el 21 de noviembre de 1902 en la que el gobernante partido conservador resultó vencedor sobre el partido liberal, que se había alzado en armas. La confrontación armada cobró un número de víctimas estimado en 100.000 personas, dejó al país en una penosa situación económica y política y facilitó que el antiguo departamento de Panamá se independizara de Colombia con el auspicio de Estados Unidos de América el 3 de noviembre de 1903. En tal estado de postración nacional, el general Rafael Reyes, un afamado militar, ganó las elecciones presidenciales para el período constitucional 1904-1910

Reyes se propuso llevar a cabo profundas reformas económicas y administrativas para reconstruir y desarrollar el país ${ }^{16}$. Dada la crisis que afrontaba, su gobierno optó por una intervención intensa del Estado en la economía, aunque no permanente sino circunstan$\mathrm{cial}^{17}$, enfocada hacia la generación de mayores ingresos fiscales y en la promoción de la productividad, tanto agrícola como industrial. Humberto Vélez nos recuerda las principales y estratégicas áreas de intervención ${ }^{18}:$ 1) el establecimiento de monopolios fiscales para nacionalizar los tributos (que eran rentas departamentales) 2) el financiamiento estatal de la inversión pública, en especial en la construcción de obra pública como carreteras y ferrocarriles; y 3)

15 Humberto Vélez-Ramírez, Rafael Reyes: Quinquenio, régimen político y capitalismo, 1904-1909, en Nueva Historia de Colombia, Tomo I, 187-214 (Editorial Planeta, Bogotá, 1989).

16 La administración Reyes se propuso, sin crear nuevas rentas, aumentar los ingresos del fisco nacional reorganizando las ya existentes; "para ello impuso un sistema de corte centralista que nacionalizó las rentas de licores, degüello y tabaco, manejadas anteriormente por los departamentos, comprometiéndose a darles una participación anual". SYlvia BeATriz Díaz, Finanzas públicas del gobierno central en Colombia, 1905-1925, 14 Historia Crítica, 59-80 (1997). Disponible en: https:// historiacritica.uniandes.edu.co/view.php/465/index.php?id=465

17 Humberto Vélez-Ramírez, Rafael Reyes, o los inicios del Estado moderno en Colombia, 21 Lecturas de Economía, 59-80, 72 (1986). Disponible en: https://aprendeenlinea.udea.edu.co/revistas/index. $\mathrm{php} /$ lecturasdeeconomia/article/view/7951/7453

18 Humberto Vélez-Ramírez, Rafael Reyes, o los inicios del Estado moderno en Colombia, 21 Lecturas de Economía, 59-80, 72 (1986). 
el establecimiento de estímulos fiscales para fomentar la industria textil.

Las iniciativas reformistas de Reyes fueron bloqueadas por el Congreso de la República, pues el Ejecutivo pretendía prescindir tanto de los políticos tradicionales como de los partidos políticos. El Congreso no solo negó la aprobación de las facultades extraordinarias para legislar por decreto que había pedido el gobierno para temas como el sistema tributario y la contratación para la construcción y operación de ferrocarriles, sino que además dilató la aprobación de normas vitales para el funcionamiento de la administración ${ }^{19}$, como fue el caso de la ley de presupuestos y gastos para la vigencia fiscal del año $1905^{20}$. El presidente Reyes superó el bloqueo con la declaración del estado de sitio, el cierre del Congreso $^{21}$ y la convocatoria a una Asamblea Nacional Constituyente y Legislativa (ANCL) el 1 de febrero de $1905^{22}$.

La ANCL se integró por tres diputados de cada uno de los nueve departamentos del país, sustituyó al Congreso, ratificó casi todos los decretos de estado de sitio dictados por el gobierno; y finalmente, aprobó varias reformas constitucionales dirigidas a concentrar el poder en el Ejecutivo: (i) Amplió el período presidencial de seis a diez años pero solo para el caso en que Reyes quisiera seguir en el cargo; ii) centralizó aún más el poder en la Nación al desintegrar los viejos estados y crear nuevos departamentos; iii) suprimió las asambleas departamentales y modificó las reglas de elección del Senado. En cuanto a la rama judicial, suprimió el Consejo de Estado y puso fin a las magistraturas vitalicias de la Corte Suprema

19 Ninguno de los proyectos de ley de contenido económico que había presentado el gobierno al Congreso había sido aprobado hacia finales de 1904. Luego de reunirse con los parlamentarios, el Ejecutivo presentó un solo proyecto que reunía autorizaciones para diferentes leyes. Pero llegó el 30 de noviembre y no se había aprobado la ley, Reyes retiró el proyecto, citó el Congreso a sesiones extraordinarias y sometió dos proyectos: uno sobre créditos adicionales y otro sobre arbitrios fiscales. Llegó el 12 de diciembre y el presidente de la Cámara le informó al gobierno que no se había podido conformar el quorum necesario para debatir el proyecto. Así terminó el año 1904 sin que la administración Reyes pudiese resolver el problema fiscal de la Nación. RoBerto Junguito \& HeRnÁn Rincón, La política fiscal en el siglo XX en Colombia, Documento preparado para el seminario Investigaciones recientes sobre historia económica colombiana, 4 y 5 de agosto de 2004, Bogotá. Disponible en: https://core.ac.uk/download/pdf/7077619.pdf?repositoryId=153

20 Eduardo Lemaitre, Rafael Reyes: biografía de un gran colombiano (4⿳a ed., Editorial Norma, Bogotá, 1994).

21 Augusto Hernández-Becerra, La revocatoria del Congreso en 1905, 162 Credencial Historia (2003). Disponible en: http://www.banrepcultural.org/revista-59

22 Decreto legislativo 29, 1 de febrero de 1905. 
de Justicia, de modo que el 1 de mayo de 1905 Reyes logró integrar el tribunal con nuevos magistrados, que podrían ser reelegidos indefinidamente ${ }^{23}$.

En 1909, Reyes parecía estar en el ocaso de su régimen, de modo que convocó a elecciones para integrar el Congreso. Aunque la oposición organizada bajo las Juntas Republicanas (luego Unión Republicana) logró un importante número de escaños parlamentarios, aún se veía lejana la salida de Reyes del poder pues el Congreso era mayoritariamente gobiernista ${ }^{24}$. Sin embargo, ante una oposición bien organizada, Reyes abandonó sigilosamente el país en junio de 1909 y su dimisión se hizo oficial el 27 de julio de 1909. El Congreso, entonces, eligió a Ramón González-Valencia como presidente de la república; en ese mismo órgano, los partidarios de la Unión Republicana, que agrupaba a conservadores y liberales que buscaban la reconciliación nacional, impulsaron la convocatoria a una asamblea constitucional.

Después de un proceso político complejo y de transición, González-Valencia convocó una Asamblea Constitucional (AC) el 25 de febrero de 1910. Ese órgano quedó conformado por quince diputados liberales y treinta y cinco conservadores. La mayoría de la AC acogía las banderas de la Unión Republicana y este órgano fue el encargado de aprobar los setenta artículos del Acto Legislativo 03. La reforma constitucional tenía como propósitos: (i) moderar el centralismo político y administrativo; (ii) limitar el poder presidencial; (iii) garantizar la separación de poderes; y (iv) fortalecer las libertades públicas (hoy conocidas como libertades civiles).

En cuanto al estado de sitio, el artículo 33 de la reforma estableció que el presidente de la república debía declarar restablecido el orden público una vez cesara la perturbación; adicionalmente, determinó que aquel sería responsable por cualquier abuso en que se hubiera incurrido durante el ejercicio de las facultades extraordinarias y que limitaba la vigencia de los decretos legislativos a la estricta duración del estado de $\operatorname{sitio}^{25}$ :

23 Artículo 3 (transitorio), del Acto reformatorio 1 de 1905. Colombia, Acto reformatorio 1 de 1905, por el cual se reforman los artículos 147 y 155 de la Constitución de la República, 27 de marzo de 1905, 12314 Diario Oficial, 30 de marzo de 1905.

24 Fernando Correa-Uribe, Republicanismo y reforma constitucional (Facultad de Ciencias Sociales y Humanas, Universidad de Antioquia, Medellín, 1996).

25 Carlos Restrepo-Piedrahita, comp., Constituciones Políticas Nacionales de Colombia (3 ${ }^{\mathrm{a}}$ ed., 
Artículo 33. En caso de guerra exterior o de conmoción interior podrá el presidente, con la firma de todos los ministros, declarar turbado el orden público y en estado de sitio toda la República o parte de ella. Mediante tal declaración el Gobierno tendrá, además de las facultades legales, las que, conforme a las reglas aceptadas por el Derecho de Gentes, rigen para la guerra entre naciones.

Los decretos que dentro de estos límites dicte al Presidente tendrán carácter obligatorio, siempre que lleven la firma de todos los ministros.

El Gobierno no puede derogar las leyes por medio de los expresados decretos. Sus facultades se limitan a la suspensión de las que sean incompatibles con el estado de sitio.

El Gobierno declarará restablecido el orden público tan pronto como haya cesado la guerra exterior o se haya reprimido el alzamiento; y dejarán de regir los decretos de carácter extraordinario que haya dictado.

Serán responsables el presidente y los ministros cuando declaren turbado el orden público sin haber ocurrido el caso de guerra exterior o de conmoción interior; y lo serán también, lo mismo que los demás funcionarios, por cualquier abuso que hubieren cometido en el ejercicio de las facultades concedidas en el presente artículo. Restablecido el orden público, el Gobierno convocará el Congreso y le pasará una exposición motivada de sus providencias.

En el caso de guerra exterior el Gobierno convocará el Congreso en el decreto en que declare turbado el orden público y en estado de sitio la república, para que se reúna dentro de los sesenta días siguientes; y si no lo convocare, podrá el Congreso reunirse por derecho propio ${ }^{26}$.

\section{Como se dijo, la misma Asamblea aprobó el Acto Legislativo 03 de 1910, que en su artículo 41 estableció la acción pública de inconstitucionalidad, en los siguientes términos:}

A la Corte Suprema se le confía la guarda de la integridad de la Constitución. En consecuencia, además de las facultades que le confieren esta y las leyes, tendrá la siguiente: Decidir definitivamente sobre la exequibilidad de los Actos Legislativos que hayan sido objetados como inconstitucionales por el Gobierno,

Universidad Externado de Colombia, Bogotá, 2003).

26 Colombia, Acto legislativo 03 de 1910, reformatorio de la Constitución Nacional, 31 de octubre de 1910, 14131 Diario Oficial, 31 de octubre de 1910. 
o sobre todas las leyes o decretos acusados ante ella por cualquier ciudadano como inconstitucionales, previa audiencia del Procurador General de la Nación.

La reforma constitucional de 1910 modificaba el diseño institucional de la Corte Suprema de Justicia pues ya no solo sería un tribunal de casación sino que tendría la responsabilidad de hacer valer la supremacía de la Carta Política y arbitrar las controversias políticas entre los poderes Legislativo y Ejecutivo - y desde luego entre los partidos políticos-. Además, en adelante, los magistrados ya no serían designados por el gobierno y confirmados por el Senado sino que el Presidente de la República propondría las ternas de candidatos para que el Congreso los eligiera para períodos de cinco años, con posibilidad de reelección indefinida.

\section{B. La propiedad en la Constitución: 1886-1910}

Para abordar la jurisprudencia de la Corte Suprema de Justicia en los inicios de su función de juez constitucional, es importante precisar los cambios normativos del derecho a la propiedad y en las reglas sobre expropiación en la Constitución entre 1886 y 1910. En primer lugar, el artículo 31 de la Constitución de 1886 determinaba que la ley garantizaría los "derechos adquiridos", aun cuando podría haber leyes que obligaran al interés privado a ceder ante el interés público por razones de utilidad pública, pero con las reglas para la plena indemnización por expropiación que fijaba el artículo 32: "En tiempo de paz nadie podrá ser privado de su propiedad en todo o en parte, sino por pena o apremio, o indemnización, o contribución general, con arreglo a las leyes. Por graves motivos de utilidad pública, definidos por el legislador, podrá haber enajenación forzosa mediante mandamiento judicial, y se indemnizará el valor de la propiedad antes de verificarse la expropiación"27.

Más adelante, ya bajo el régimen del general Reyes apareció un cambio que refleja muy bien el espíritu de la administración de crear las condiciones necesarias para realizar obras de infraestructura y el desarrollo de las comunicaciones. En efecto, el 5 de abril de 1905,

27 Carlos Restrepo-Piedrahita, comp., Constituciones Políticas Nacionales de Colombia (3 ${ }^{\mathrm{a}}$ ed., Universidad Externado de Colombia, Bogotá, 2003). Colombia, Constitución Política de 1886, 5 de agosto de 1886 . 
la ANCL aprobó el Acto Legislativo $06^{28}$ que sustituyó parcialmente el mencionado artículo 32 de la Constitución de 1886. Por una parte, la reforma mantenía la regla de que en tiempo de paz nadie podría ser privado de su propiedad, salvo en casos determinados mediante leyes expresas por contribución general o por motivos de utilidad pública definidos por el legislador, previa indemnización. La novedad consistía en que distinguía los casos de utilidad pública relacionados con vías de comunicación, que no se indemnizarían con el pago del valor de las franjas de terreno utilizadas en esas vías, ya que se entendía que esos predios se beneficiaban con la obra; aunque sí se dejaba la posibilidad de pagar la diferencia en caso de que esa franja tuviera un mayor valor. De ese modo, constitucionalizaba la "valorización" por obra pública y así hacía posible la construcción de vías sin que en todos los casos el Estado tuviere que pagar el valor de los predios utilizados para esas obras.

Finalmente, el Acto Legislativo 03 de 1910 reformó el Acto Legislativo 06 de 1905 y restableció el mismo texto del artículo 32 de la Constitución de 1886, es decir, derogó la regla creada por la ANCL sobre valorización por obra pública para vías de comunicación.

Enseguida se analiza uno de los primeros juicios de constitucionalidad de la Corte Suprema de Justicia a los decretos de estado de sitio dictados en tiempos del general Reyes, bajo el nuevo diseño institucional de la reforma constitucional de 1910.

\section{La sentencia del 11 de noviembre de 1912}

Un poco más de dos años después de haberse establecido la acción pública de inconstitucionalidad, llegó a la Corte Suprema de Justicia una de las primeras demandas ciudadanas en contra de decretos dictados por el gobierno del general Reyes bajo el régimen de estado de sitio. El tribunal que debía decidir el asunto estaba conformado por nueve magistrados provenientes de los partidos liberal y conservador. Siete de ellos habían sido nombrados por el presidente Ramón González-Valencia y dos más elegidos por la AC.

28 Colombia, Acto legislativo 06 de 1905, por el cual se sustituye el artículo 32 de la Constitución Nacional, 12323 Diario Oficial, 10 de abril de 1905. Disponible en: http://www.suin-juriscol.gov. co/viewDocument.asp?id=1000200 
Los liberales eran: Constantino Barco, presidente de la Corte ${ }^{29}$; Tancredo Nannetti, vicepresidente ${ }^{30}$; Manuel José Angarita ${ }^{31}$ y Luis Eduardo Villegas ${ }^{32}$. Los magistrados de origen conservador eran: Emilio Ferrero $^{33}$, Rafael Navarro y Eusse ${ }^{34}$, Bartolomé Rodríguez ${ }^{35}$, Augusto Samper ${ }^{36}$ y Alberto Suárez-Murillo ${ }^{37}$.

A esta Corte le correspondió decidir sobre la demanda de inconstitucionalidad presentada en contra del decreto legislativo 40 de 28 de febrero de 1905, sobre desecación de lagunas, ciénagas y pantanos, así como contra la Ley 6 del 5 de abril del mismo año que ratificó tal decreto. El general Reyes había dictado el decreto 40 en uso de facultades de estado de sitio, mientras que la Ley 6 había sido promulgada por la Asamblea Nacional Constituyente y Legislativa, que ratificaba seis decretos "que han tenido origen en el Ministerio de Obras Públicas" 38 .

Las medidas demandadas establecían que el gobierno "deslindaría lagos, lagunas, ciénagas y pantanos de propiedad nacional, de los predios ribereños pertenecientes a particulares". Para esto, el decreto 40 de 1905 declaraba que eran propiedad de la Nación "los terrenos que hayan estado inundados u ocupados por las aguas en

29 Abogado destacado, del Norte de Santander.

30 Caucano, hizo parte de la Unión Republicana, abogado de la Universidad Externado de Colombia.

31 Era un destacado líder del partido liberal. Antes de llegar a la Corte, ya había sido alcalde de Bogotá, entre 1872 y 1873 .

32 Antioqueño, fue secretario de los ministerios de Guerra y Marina en los gobiernos liberales de Santiago Pérez [1 de abril de 1874-1 de abril de 1876] y Aquileo Parra [1 de abril de 1876-1 de abril de 1878], magistrado del Tribunal Superior de Medellín, representante a la Cámara, senador y columnista de El Tiempo.

33 Integró la Asamblea Constitucional de 1910 como diputado por la circunscripción electoral de Cúcuta; luego de estar en la Corte, fue ministro en varios gabinetes de la hegemonía conservadora entre 1914 y 1928.

34 Estuvo en la Asamblea Constitucional de 1910 como diputado por la circunscripción electoral de Cúcuta y conformó la Unión Republicana.

35 Antes de llegar a la Corte había sido diputado a la Asamblea de Cundinamarca. Después fue congresista, por ejemplo, hizo parte de la Comisión Legislativa que eligió el Congreso en 1909 para la redefinición político-administrativa del territorio. Luego fue diputado a la Asamblea Nacional de 1910 en representación de la circunscripción electoral de Tunja. Estuvo en la Corte Suprema hasta 1924.

36 Antes de llegar a la Corte, fue dirigente del grupo de los conservadores históricos opositores del gobierno del presidente Manuel Antonio Sanclemente [7 de agosto de 1898-31 de julio de 1900] y ministro del gabinete del vicepresidente golpista José Manuel Marroquín [31 de julio de 1900-7 de agosto de 1904]. Luego presidió la Cámara de Representantes y después integró la Asamblea Constitucional de 1910.

37 Tolimense, fue representante a la Cámara y senador.

38 Colombia, Ley 6 de 1905, por el cual se ratifican algunos Decretos de carácter legislativo que han tenido origen en el Ministerio de Obras Públicas, 12323 Diario Oficial, 10 de abril de 1905. Disponible en: http://www.suin-juriscol.gov.co/viewDocument.asp?id=1695117 
los últimos 10 años". De igual modo, autorizaba al gobierno a dar en pago de las obras del desagüe de esos cuerpos de agua, toda o parte de la obra que quede en seco en lo atinente a los terrenos de los particulares que hubieren estado ocupado por las aguas desde hace más de diez años. Por último, establecía una contribución por parte del propietario del predio beneficiado por el desecamiento, que pagaría a quien hubiese realizado la obra.

Como se puede notar, las medidas acusadas de inconstitucionalidad se enmarcaban en las políticas de la administración Reyes: por un lado, promovían la obra pública al desecar los cuerpos de agua, pero no con financiación estatal sino por parte de los propietarios beneficiados, que pagarían a aquellos que realizaran las obras; y por otro, buscaba desarrollar la actividad agrícola en las áreas que se desecarían y que eran ampliamente conocidas por su gran fertilidad $^{39}$. Las dos normas además se relacionaban con la mencionada reforma constitucional del Acto Legislativo 06 de 1905, que buscaba que el Estado construyera vías de comunicación, sin que en todos los casos tuviese que pagar por los predios usados en tales obras. Por último, el decreto 40 de 1905 le entregaba al Ministerio de Obras Públicas, institución recién creada y clave para la ejecución de las políticas del gobierno, la regulación de los juicios de expropiación necesarios para darle cumplimiento al decreto.

La Corte Suprema de Justicia, con la ponencia del magistrado Bartolomé Rodríguez, decidió sobre la demanda el 21 de noviembre de $1912^{40}$. Según los demandantes, el decreto 40 del 28 de febrero de 1905 vulneraba la Constitución porque había sido dictado por un órgano que carecía de competencia para ello pues el Presidente de la República lo había expedido al amparo del estado de sitio cuando "no había en el país guerra exterior ni había en él conmoción interior que autorizase al Presidente para expedir decretos legislativos, de acuerdo con el artículo 121 de la Constitución,

39 Es el caso de la laguna de Fúquene, en Cundinamarca.

40 Noventa y dos años después, bajo la Constitución de 1991, el decreto legislativo 40 de 1905 y el artículo 723 del Código Civil fueron demandados por considerar que vulneraban el derecho de propiedad. La Corte Constitucional señaló que ya había obrado la cosa juzgada sobre el decreto pues la Corte Suprema lo había declarado exequible en 1912; por tanto, rechazó los cargos de la demandante. En cuanto al artículo 723 del Código Civil, llegó a la conclusión de que este no vulneraba la Carta Política. Colombia, Corte Constitucional, Sentencia C-1172-04, 23 de noviembre de 2004, magistrada ponente Clara Inés Vargas-Hernández. Disponible en: http://www.corteconstitucional. gov.co/relatoria/2004/C-1172-04.htm 
pues la Nación estaba en paz, ya porque en el supuesto de que el orden público estuviese turbado entonces y se hubiera declarado la República o parte de ella en estado de sitio, tampoco tenía atribución el Presidente para darlo, por cuanto el objeto único de las facultades extraordinarias, o en su defecto, de las que consagra el Derecho de Gentes, de que el artículo constitucional mencionado investía para ese caso al Presidente, era el de defender la Nación o reprimir el alzamiento, y que a ninguno de estos objetos provenía ni aun indirectamente el decreto" $"$.

Los demandantes también le pidieron a la Corte de manera subsidiaria que, "suponiendo que el Presidente hubiera tenido potestad legislativa para dictar el decreto acusado", se declarara la inconstitucionalidad del mismo por atentar contra los derechos adquiridos y el derecho de propiedad reconocidos por la Constitución. A su juicio, tal vulneración se producía porque el decreto ordenaba deslindar "los lagos, ciénagas y pantanos de propiedad nacional, de los predios ribereños pertenecientes a particulares" y para tal deslinde se declaraban de propiedad de la Nación "los terrenos que hayan estado inundados $u$ ocupados por las aguas en los últimos diez años"43; de modo que pasaban a ser de la Nación lo que les pertenecía a aquellos particulares propietarios de los terrenos.

Según los demandantes, el decreto también atentaba contra el derecho de propiedad de los "dueños de las aguas" pues establecía que el gobierno podía dar en propiedad a las personas con quienes contratase el desagüe de lagos, lagunas, ciénagas y pantanos de la Nación, los terrenos que quedaran en seco después de ejecutada tal obra. Además, acusaban a la medida de vulnerar la Constitución porque establecía que una vez se produjese el desagüe, quienes hubiesen ejecutado esas obras cobrarían a los propietarios de predios colindantes la diferencia entre el avalúo de tales predios fijado antes de la obra y el asignado luego de ella, con lo cual se imponía a los

41 Colombia, Corte Suprema de Justicia, Sentencia de 21 de noviembre de 1912, magistrado ponente Bartolomé Rodríguez, Gaceta Judicial, Tomo 22 (1913-1914), 1091-1146, 10.

42 Decreto número 40 de 1905, citado por la Corte Suprema de Justicia, sentencia del 21 de noviembre de 1912.

43 Colombia, Corte Suprema de Justicia, Sentencia de 21 de noviembre de 1912, magistrado ponente Bartolomé Rodríguez, Gaceta Judicial, Tomo 22 (1913-1914), 1091-1146. 
propietarios una contribución sin fundamento constitucional ${ }^{44}$. Por último, que como el decreto ordenaba que el empresario que llevase a cargo la mencionada obra tendría acción ejecutiva contra el propietario beneficiado que se negare a pagarle el beneficio recibido en su propiedad, se establecía una condena contra este último sin haber sido oído o vencido en juicio, lo cual contrariaba la "Carta Fundamental" 45 . Estas eran las normas constitucionales que los demandantes consideraban infringidas ${ }^{46}$ :

Artículo 31: Los derechos adquiridos con justo título con arreglo a las leyes civiles por personas naturales o jurídicas, no pueden ser desconocidos ni vulnerados por leyes posteriores. Cuando de la aplicación de una ley expedida por motivos de utilidad pública, resultaren en conflicto los derechos de particulares con la necesidad reconocida por la misma ley; el interés privado deberá ceder al interés público. Pero las expropiaciones que sea preciso hacer requieren plena indemnización con arreglo al Artículo siguiente.

Artículo 32: En tiempo de paz nadie podrá ser privado de su propiedad en todo ni en parte, sino por pena, o apremio, o indemnización, o contribución general, con arreglo a las leyes. Por graves motivos de utilidad pública, definidos por el Legislador, podrá haber lugar a enajenación forzosa, mediante mandamiento judicial, y se indemnizará el valor de la propiedad, antes de verificar la expropiación.

La Corte resolvió la demanda pero se abstuvo de analizar si el gobierno del presidente Reyes o la Asamblea Nacional eran competentes para dictar el decreto 40 y la Ley 6 de 1905, respectivamente, pues consideró que para tomar una decisión bastaba con examinar si ambas normas vulneraban el derecho de propiedad. Entonces, optó por estudiar los cargos según los cuales la medida afectaba el derecho de propiedad y los derechos adquiridos. En primer lugar, determinó que, en efecto, el decreto vulneraba el artículo 32 de la Constitución, que consagraba el "derecho de propiedad de los particulares", así como el artículo 31, que garantizaba "los derechos adquiridos legítimamente salvo los casos en que han de ceder a la

44 Medida que haría parte de la trayectoria de la denominada Contribución por valorización de la historia tributaria nacional.

45 Colombia, Corte Suprema de Justicia, Sentencia de 21 de noviembre de 1912, magistrado ponente Bartolomé Rodríguez, Gaceta Judicial, Tomo 22 (1913-1914), 1091-1146, 9.

46 Carlos Restrepo-Piedrahita, Constitución Política de la República de Colombia de 1886, en Constituciones Políticas Nacionales de Colombia, 341-590, 395 (3ª ed., Carlos Restrepo-Piedrahita, comp., Universidad Externado de Colombia, Bogotá, 2003). 
utilidad pública con la debida indemnización"47. En ese orden de ideas, estimó que la medida demandada pasaba a la Nación unas tierras que eran propiedad de los particulares, sin que esta ordenara indemnización alguna a favor de los afectados.

Uno de los aspectos más llamativos del raciocinio de la Corte es su desplazamiento desde la Constitución hacia el Código Civil, que en últimas fue el material jurídico que sirvió de fundamento a la decisión. Tal postura podría explicarse por la trayectoria institucional de una Corte Suprema de Justicia que había ejercido como tribunal de casación civil antes de la reforma de 1910; además, porque hacía parte de una comunidad interpretativa de juristas influenciada por el predominio de la doctrina y de la legislación civil como materiales para aproximarse a los contenidos de la Constitución, y que tal vez heredaba de los tiempos de la célebre Ley 153 de 1887 que disponía la supremacía de la ley sobre la propia Constitución de $1886^{48}$.

Tal "reenvío" a la legislación civil para juzgar la constitucionalidad de una norma es palpable cuando la Corte argumenta que si bien el Libro 2 del Título 3 del Código Civil ("de los bienes de la Unión" - La Nación) determinaba que la Nación tenía derechos sobre lagos, ríos y otras aguas, ni el presidente de la república ni la Asamblea Nacional estaban autorizados para dictar normas como las acusadas porque el artículo 684 del mismo Código establecía que: "No obstante lo prevenido en este capítulo y en el de la accesión, relativamente al dominio de la Unión sobre los ríos, lagos e islas, subsistirán en ellos los derechos adquiridos por particulares, de acuerdo con la legislación anterior a este Código"49. Así, para el tribunal este artículo debía interpretarse en el sentido de que los

47 Colombia, Corte Suprema de Justicia, Sentencia de 21 de noviembre de 1912, magistrado ponente Bartolomé Rodríguez, Gaceta Judicial, Tomo 22 (1913-1914), 1091-1146, 10.

48 El artículo 6 de la Ley 153 disponía: "Una disposición expresa de ley posterior a la Constitución se reputa constitucional y se aplicará aun cuando parezca contraria a la Constitución”. Colombia, Ley 153 de 1887, por la cual se adiciona y reforma los códigos nacionales, la Ley 61 de 1886 y la 57 de 1887, 7151 y 7152 Diario Oficial, 28 de agosto de 1887. Disponible en: http://www.alcaldiabogota. gov.co/sisjur/normas/Norma1.jsp?i=15805

49 Colombia, Corte Suprema de Justicia, Sentencia de 21 de noviembre de 1912, magistrado ponente Bartolomé Rodríguez, Gaceta Judicial, Tomo 22 (1913-1914), 1091-1146, 10. Colombia, Ley 84 de 1873, Código Civil de los Estados Unidos de Colombia, 26 de mayo de 1873, 2867 Diario Oficial, 31 de mayo de 1873. Disponible en: http:/www.suin-juriscol.gov.co/viewDocument. asp?ruta=Leyes/1827111. Colombia, Ley 57 de 1887, sobre adopción de códigos y unificación de la legislación nacional, 15 de abril de 1887, 7019 Diario Oficial, 20 de abril de 1887. Disponible en: http://www.secretariasenado.gov.co/senado/basedoc/codigo_civil.html, http://www.alcaldiabogota. gov.co/sisjur/normas/Norma1.jsp?i=39535 
terrenos ocupados por las aguas no pertenecían a la Nación aun cuando tal ocupación hubiese ocurrido durante los diez años anteriores a la expedición del decreto legislativo dictado por el Ejecutivo y por tanto, las disposiciones acusadas desconocían abiertamente el derecho de dominio de los propietarios de los terrenos ${ }^{50}$.

La Corte también estimó que el decreto 40 de 1905 menoscababa el derecho de propiedad y los derechos adquiridos reconocidos por la Constitución, porque les imponía a los propietarios de los terrenos colindantes a donde se hubiesen realizado las obras de desecación el pago del "valor del beneficio" a favor de los ejecutantes de tales obras, es decir, del "aumento de valor" de las propiedades beneficiadas (valorización). En su criterio, tal disposición no correspondía a una "contribución general, indemnización, pena o apremio", sino a una privación del derecho de propiedad que la Carta Política prohibía. De igual modo, determinó que como de esta disposición dependía aquella que permitía al ejecutor de las obras recurrir a la acción ejecutiva en contra del propietario beneficiario renuente, esa también devenía en inconstitucional. Y por último, que la Ley 6 de 1905 era inconstitucional en cuanto había ratificado las disposiciones del decreto legislativo 40 de 1905.

En suma, al abstenerse de juzgar la constitucionalidad del decreto legislativo 40 de 1905, dictado por el gobierno de Reyes bajo el estado de sitio, y de la Ley 6 de 1905 aprobada por la ANCL, por el cargo de que el gobierno se había excedido en sus facultades bajo el estado de sitio, la Corte les reconocía plena legalidad a ambos cuerpos normativos. Es decir, evitaba tener que evaluar si el régimen de Reyes había obrado en el marco de la Constitución, pues recordemos que tanto el decreto como la ley fueron dictados luego de que Reyes cerró el Congreso, mediante un decreto de estado de sitio; y la ley fue aprobada por la ANCL, que ejerció funciones legislativas en nombre del Congreso de la República. De hecho, al analizar si las normas demandadas habían vulnerado el derecho de propiedad y los derechos adquiridos garantizados por la Constitución de 1886, la Corte abordaba el juicio de constitucionalidad

50 Colombia, Corte Suprema de Justicia, Sentencia de 21 de noviembre de 1912, magistrado ponente Bartolomé Rodríguez, Gaceta Judicial, Tomo 22 (1913-1914), 1091-1146, 10. 
como si aquel decreto y aquella ley hubiesen sido expedidos en tiempos de normalidad institucional ${ }^{51}$.

Pero el fallo no fue unánime. Tres magistrados de origen liberal salvaron su voto: Tancredo Nannetti lideró la opinión disidente y a ella se plegaron Manuel José Angarita y Constantino Barco. Según el salvamento, las normas acusadas no vulneraban el derecho de propiedad a la luz del Código Civil. En primer lugar, porque la Corte había interpretado de manera errónea las normas del decreto 40 de 1905 pues este de ningún modo ordenaba que las cuencas de todos los lagos, ciénagas o pantanos que hubiese en el territorio nacional - no obstante muchos de estos fuesen propiedad de los particulares - se declararan propiedad del Estado por el solo hecho de haber estado ocupados por las aguas durante los últimos diez años; sino que el decreto lo que ordenaba era el deslinde de las aguas de propiedad nacional, y prevenía que para esos efectos se reputaban de propiedad de la Nación los terrenos que hayan sido inundados u ocupados por las aguas en los últimos diez años. Entendiéndose, claramente, a partir de lo anterior, que se refería a aguas de propiedad de la Nación, pues el decreto lo que ordenaba era el deslinde de los lagos, lagunas, ciénagas y pantanos de propiedad del Estado.

Así las cosas, opinaba el salvamento, también en clave de legislación civil, que las disposiciones acusadas como inconstitucionales no hacían nada distinto a lo ordenado por las reglas sobre accesión del artículo 723 del Código Civil: "Si una heredad ha sido inundada, el terreno restituido por las aguas, dentro de los diez años subsiguientes, volverá a sus antiguos dueños". Es decir, en su opinión si los terrenos inundados por más de diez años pasan por accesión al dueño del río o lago que originó la inundación, bajo esa figura el Estado podía alegar su derecho cuando "las aguas ocupantes de heredadas aledañas le pertenecen”, pero de ningún modo en virtud del artículo 675 del mismo Código. Para reforzar su postura, el salvamento de voto recurrió al derecho comparado y a la historia del origen de la legislación civil colombiana, y recordó que sobre la materia tanto el Código Civil colombiano como el chileno siguieron

51 Por oposición, la anormalidad institucional en parte fue reconocida por la Asamblea Constitucional de 1910, que en el artículo "E" del Acto Legislativo 03 de 1910 determinó que quedaban derogados todos los Actos Legislativos expedidos por la ANCL anteriores a él. 
"la tradición romana" y la española en lugar de acudir al Código Civil francés ${ }^{52}$ :

En el mismo sentido se pronunció el Derecho español. Así en la Partida $3^{a}$, Ley 32, Título 38 se lee: "Cúbrense de agua a las vegadas, las heredades de algunos omes por las avenidas de los ríos, de manera que fincan cubiertas muchos días; e como quier que los señores dellas pierdan la tenencia en cuanto están cubiertas, con todo eso en salvoles finca el señorío que en ellas avían. Ca luego que sean descubiertas, e que el agua tornare a su lugar, usarán dellas también come en ante fazian".

Nannetti también señaló que el Código Civil francés no abordó la materia, de modo que: "no nos puede servir para ilustrar el punto las exposiciones de los comentaristas de esa legislación”. Y agregó:

El señor Bello, siguiendo los antecedentes romanos y españoles, consignó así el principio en el Código Civil chileno: "Si una heredad ha sido inundada por un río, el terreno restituído después por las aguas volverá a sus antiguos dueños", pero ese artículo no fue aceptado por la Comisión encargada de dicho proyecto, y se sustituyó por el 653 del Código, que puso como límite el tracto de diez años, para que las tierras restituídas por las aguas volvieran a sus antiguos dueños ${ }^{53}$.

Luego de mencionar a comentaristas del Código Civil chileno, como Jacinto Chacón y Barrios y Robustiano Vera, citados por el tratadista colombiano Fernando Vélez ${ }^{54}$, el magistrado Nannetti dijo que no cabía duda de que el artículo 723 del Código Civil colombiano solo tendría sentido si se interpretaba según lo expresado en el salvamento de voto:

Bien puede suceder que la doctrina de las legislaciones romana y española acogida por don Andrés Bello en su proyecto de Código Civil chileno y reproducida en los artículos 752 del Código Civil caucano y 740 del cundinamarqués, esté más de acuerdo con los principios, porque no debe hacerse cargar a los propietarios con las consecuencias del caso fortuito de la inundación; pero es lo cierto

52 Colombia, Corte Suprema de Justicia, Sentencia de 21 de noviembre de 1912, magistrado ponente Bartolomé Rodríguez, salvamento de voto del magistrado Tancredo Nannetti, Gaceta Judicial, Tomo 22 (1913-1914), 1091-1146, 13.

53 Colombia, Corte Suprema de Justicia, Sentencia de 21 de noviembre de 1912, magistrado ponente Bartolomé Rodríguez, salvamento de voto del magistrado Tancredo Nannetti, Gaceta Judicial, Tomo 22 (1913-1914), 1091-1146, 13.

54 Los comentaristas del Código Civil de Chile a que se refiere la Corte son: JACINTO ChACón Y BARRIOS, Exposición razonada y estudio comparativo del Código Civil Chileno (Imprenta del Mercurio, Valparaíso, 1868). Y Robustiano Vera, Código Civil de la República de Chile, comentado y explicado (Imprenta Nacional, Santiago de Chile, 1892-1897). 
que el artículo 723 del Código Civil nacional se aparta de ese criterio, probablemente con el objeto de estimular a los dueños con la sanción de la pérdida de sus terrenos inundados si se descuidan en desecarlos por más de diez años.

Así, los tres magistrados disidentes concluyeron que el parágrafo del Decreto Legislativo 40 de 1905 sí era constitucional pues estaba conforme con el artículo 723 del Código Civil: "El terreno inundado por más de diez años pasa a ser parte integrante del receptáculo de las aguas, y sigue la suerte jurídica de estas".

Por otra parte, fuera del debate sobre la legislación civil aplicable al caso sometido a juicio de constitucionalidad, en la Corte hubo una voz dispuesta a abrir el debate constitucional en torno a los límites del Ejecutivo bajo el estado de sitio: el magistrado de origen liberal Manuel José Angarita expresó su apoyo al concepto del Procurador General de la Nación, que le había pedido al tribunal declarar la nulidad de la ley y del decreto acusado, porque ambos "se dictaron por autoridades incompetentes" 55 .

De este modo, en una de las primeras sentencias dictadas desde que se había creado la acción pública de inconstitucionalidad, la Corte Suprema de Justicia prefirió tomar una distancia suficiente de la arena política y evadir el juicio a los límites del Ejecutivo bajo el estado de sitio. Con esto evitó pronunciarse sobre el uso y el abuso del régimen de excepción bajo el cual gobernó el general Reyes por cinco años. Al mismo tiempo, cumplió el papel de proteger un derecho de profundo raigambre liberal como el de la propiedad privada, consagrado en la Constitución de 1886 con su reforma del Acto Legislativo 03 de 1910. Así, el tribunal cumplía la nueva y compleja función de garantizar la supremacía constitucional, aunque dejó intacto el poder presidencial.

55 Colombia, Corte Suprema de Justicia, Sentencia de 21 de noviembre de 1912, magistrado ponente Bartolomé Rodríguez, salvamento de voto del magistrado Manuel José Angarita, Gaceta Judicial, Tomo 22 (1913-1914), 1091-1146, 12. 


\section{LA CORTE SUPREMA Y LA DEFENSA DE LA PROPIEDAD PRIVADA BAJO EL ESTADO DE SITIO: 1954}

\section{A. La propiedad privada en la Constitución: 1936 a 1954}

Antes de avanzar hacia la segunda sentencia de la Corte Suprema de Justicia sobre expropiación que examina este trabajo, es importante recordar que el régimen constitucional de la propiedad privada sufrió un cambio trascendental con la reforma liberal de 1936. En efecto, el Acto Legislativo 01 del 5 de agosto de $1936^{56}$, obra de la denominada Revolución en Marcha impulsada por el primer gobierno del presidente Alfonso López Pumarejo ${ }^{57}$ [7 de agosto de 1934-7 de agosto de 1938], modificó la Constitución de 1886 y estableció:

Artículo 10: Se garantizan la propiedad privada y los demás derechos adquiridos con justo título, con arreglo a las leyes civiles, por personas naturales o jurídicas, los cuales no pueden ser desconocidos ni vulnerados por leyes posteriores. Cuando de la aplicación de una ley expedida por motivos de utilidad pública o interés social, resultaren en conflicto los derechos de particulares

56 Colombia, Acto Legislativo 01 de 1936, reformatorio de la Constitución, 5 de agosto de 1936, 23263 Diario Oficial, 22 de agosto de 1936. Disponible en: http://www.suin-juriscol.gov.co/viewDocument. asp?id=1824914

57 Sobre la reforma constitucional de 1936 y la Revolución en Marcha: Álvaro Tirado-Mejía \& Magdala Velásquez, La reforma constitucional de 1936 (Fundación Friederich Naumann, Oveja Negra, Bogotá, 1982). Álvaro Tirado-Mejía, López Pumarejo, la Revolución en Marcha, en Nueva Historia de Colombia, Vol. I, Historia Política 1886-1946, 305-348 (Álvaro Tirado-Mejía, coord., Planeta, Bogotá, 1989). SANDRA BOTERO, La reforma constitucional de 1936, el Estado y las politicas sociales en Colombia, 33 Anuario Colombiano de Historia Social y de la Cultura, ACHSC, 85-109 (2006). Disponible en: http://www.bdigital.unal.edu.co/14332/1/3-8216-PB.pdf 
con la necesidad reconocida por la misma ley, el interés privado deberá ceder al interés público o social.

La propiedad es una función social que implica obligaciones.

Por motivos de utilidad pública o de interés social definidos por el legislador, podrá haber expropiación, mediante sentencia judicial e indemnización previa.

Con todo, el legislador, por razones de equidad, podrá determinar los casos en que no haya lugar a indemnización, mediante el voto favorable de la Mayoría absoluta de los miembros de una y otra Cámara ${ }^{58}$.

Como se puede apreciar, la reforma que se alineaba con el Constitucionalismo Social, determinaba que la propiedad tenía una función social; que el interés privado cedería ante el interés público en los casos en que fuere necesario expedir una ley de "utilidad pública"; y se agregaba el interés social como un motivo más para proceder a ordenar una expropiación. Y avanzaba hasta establecer que en algunos casos no obraría la indemnización por motivos de utilidad pública o interés social, si así lo determinaba el Congreso de la República mediante una ley. Así, con la reforma de 1936 se modificaba radicalmente el régimen constitucional de protección de la propiedad. Esas reglas sobre la propiedad y la expropiación del Acto Legislativo 01 de 1936 se mantendrían vigentes incluso hasta la Constitución de 1991.

\section{B. El golpe de Estado del general Rojas Pinilla y la Corte de 1954}

El 13 de junio de 1953, el general Gustavo Rojas Pinilla, comandante general de las Fuerzas Armadas, asumió el Poder Ejecutivo tras dar un golpe de Estado al presidente constitucional Laureano Gómez, quien había sido elegido para el período 1950-195459. Rojas llegó al poder con el apoyo de un sector del partido conservador opuesto a Gómez y el beneplácito de la dirigencia del partido liberal, gran opositor del gobierno. Ejerció el Poder Ejecutivo hasta junio de

58 Negrillas agregadas al original.

59 La Asamblea Nacional Constituyente (ANAC), que en tiempos del gobierno de Laureano Gómez había sido establecida por el Congreso con el único fin de reformar la Constitución, ratificó a Rojas en su cargo. La ANAC funcionó hasta 1957. 
1957, cuando se lo entregó a la Junta Militar de Gobierno. Tanto Rojas como la Junta gobernaron por medio de decretos legislativos al amparo del estado de sitio ${ }^{60}$.

La Corte Suprema de Justicia se unió a las voces mayoritarias que saludaban la llegada del nuevo régimen. No obstante, pasaron pocos meses para que empezaran los roces ${ }^{61}$. El 5 de noviembre de 1953, el gobierno anunció que haría una profunda reforma a la justicia. Por ejemplo, propuso crear un Tribunal de Garantías Constitucionales (TGC) que se ocuparía del control constitucional de las leyes y de los decretos de estado de sitio. El TGC lo conformarían los presidentes de las Salas de la Corte Suprema de Justicia y del Consejo de Estado más tres miembros designados por el presidente de la República; pero como a los magistrados de la Corte y del Consejo los designaría el mismo general Rojas, en últimas el TGC sería puesto por el Ejecutivo ${ }^{62}$.

Más adelante, el 11 de noviembre de 1953, Rojas señaló públicamente al poder judicial de estar politizado, de no ser profesional y demandó una reforma urgente. Estas acusaciones generalizadas produjeron la renuncia de todos los magistrados de la Corte Suprema de Justicia ${ }^{63}$. Rojas pronto dio por superada la "crisis" judicial y dictó el decreto legislativo 3110, del 27 de noviembre de $1953^{64}$, que conformaba paritariamente la corporación con magistrados liberales y conservadores. Los liberales eran: Luis Felipe Latorre ${ }^{65}$,

60 El estado de sitio se mantuvo vigente hasta 1958. Fueron miles los decretos legislativos dictados durante ese período.

61 Para un estudio sobre el poder judicial bajo dictaduras: Gretchen Helmke, Courts under Constraints: Judges, Generals and Presidents in Argentina (Cambridge University Press, Cambridge, 2012). Lisa Hilbink, Judges beyond Politics in Democracy and Dictatorship: Lessons from Chile (Cambridge University Press, New York, 2007). Para un estudio comparado global, que incluye Chile, Argentina y Colombia: Tom Ginsburg \& Tamir Moustafa, eds., Rule by Law: The Politics of Courts in Authoritarian Regimes (Cambridge University Press, Cambridge, 2008).

62 Mario Alberto Cajas-Sarria, La justicia constitucional del general Gustavo Rojas Pinilla: entre el Tribunal de Garantías Constitucionales y la Sala de Negocios Constitucionales, Colombia, 1953-1957, 17 Revista de Historia Constitucional, 273-307, 282 (2016). Disponible en: http://www. historiaconstitucional.com/index.php/historiaconstitucional/article/view/464/421

63 Mario Alberto Cajas-SArria, La justicia constitucional del general Gustavo Rojas Pinilla: entre el Tribunal de Garantías Constitucionales y la Sala de Negocios Constitucionales, Colombia, 19531957, 17 Revista de Historia Constitucional, 273-307, 282 (2016).

64 Colombia, Decreto legislativo 3110 de 1953, por el cual se acepta la renuncia de la Corte Suprema de Justicia y se designa en interinidad nueva Corte, 27 de noviembre de 1953, 28359 Diario Oficial, 30 de noviembre de $1953,1$.

65 Fue profesor en varias universidades y abogado de la Presidencia de la República en la administración del presidente liberal Enrique Olaya-Herrera [1930-1934]. 
Carlos Arango-Vélez ${ }^{66}$, Aníbal Cardozo-Gaitán ${ }^{67}$, Darío Echandía $^{68}$, Eduardo Rodríguez-Piñeres ${ }^{69}$, Ricardo Jordán-Jiménez ${ }^{70}$, Néstor Pineda ${ }^{71}$ y Antonio Rocha ${ }^{72}$. Los conservadores eran: Roberto Goenaga ${ }^{73}$, Fernando Londoño ${ }^{74}$, Germán Orozco-Ochoa ${ }^{75}$, José J. Gómez ${ }^{76}$, Guillermo Salamanca ${ }^{77}$, Alberto Zuleta-Ánge ${ }^{78}$, Manuel Barrera-Parra ${ }^{79}$ y Domingo Sarasty ${ }^{80}$.

\title{
C. La Corte Suprema y los límites a la propiedad fijados por medidas de estado de sitio: 1954
}

\author{
Ante la Corte Suprema que se posesionó en febrero de 1954 se \\ presentaron varias demandas de inconstitucionalidad en contra de \\ decretos legislativos dictados por el Ejecutivo al amparo del estado \\ de sitio. Algunos de esos juicios de constitucionalidad le significa-
}

66 Penalista. Antes de llegar a la Corte, fue candidato presidencial disidente del partido liberal en 1942. Había sido alcalde de Bogotá y ministro de guerra del gabinete de Olaya-Herrera (1931).

67 Antes de llegar a la Corte, fue gobernador del Huila y diputado a la Asamblea del mismo departamento. Había estado en la Corte entre 1935 y 1939, y de 1940 a 1949. Fue el primer Registrador Nacional del Estado Civil (1949).

68 Uno de los más influyentes pensadores y dirigentes liberales del siglo XX. En calidad de designado a la Presidencia, ejerció como presidente de la república en varias ocasiones entre 1943-1944 y 19601967. Había sido juez civil de circuito y magistrado del Tribunal Superior del Huila. A él se atribuye gran parte del giro del partido liberal hacia el derecho social en 1930; artífice de la Revolución en Marcha que condujo el presidente Alfonso López Pumarejo (1934-1938) y de la reforma constitucional de 1936. Fue ministro de gobierno (1934-1935) y de relaciones exteriores (1942-1943) en los gobiernos de Alfonso López-Pumarejo y de justicia (1967-1968) en el de Carlos Lleras-Restrepo.

69 Era uno de los juristas más destacados de la primera mitad del siglo XX colombiano.

70 Penalista. Fue magistrado de la Sala Penal del Tribunal Superior de Cali. Ya había estado en la Corte en 1944. Profesor de derecho penal en las universidades Externado y Nacional de Colombia.

71 Oriundo del departamento de Córdoba, fue ministro de minas y petróleos (1941-1942, 1942-1943) en los gobiernos de Eduardo Santos [7 de agosto de 1938-7 de agosto de 1942] y Alfonso López Pumarejo [7 de agosto de 1942-7 de agosto de 1945].

72 Era un destacado jurista. Ya había estado en la Corte en 1935. Luego fue ministro de industria y trabajo, y de gobierno, de relaciones exteriores y de educación en la primera y segunda administración de López (1937-1938, 1943-1945). Fue decano de la Facultad de Derecho de la Universidad Nacional.

73 Ya había sido magistrado de la Corte y gobernador del departamento de Magdalena.

74 Abogado de la Universidad del Cauca. Antes de llegar a la Corte, fue representante a la Cámara, juez, ministro de relaciones exteriores y embajador.

75 Antioqueño.

76 Era un destacado abogado civilista.

77 Fue representante a la Cámara, miembro del Gran Consejo Electoral y ministro de economía y de industria y comercio del presidente Mariano Ospina-Pérez (1948).

78 Era un reputado abogado civilista. Había sido decano de Derecho de la Universidad Nacional unos meses antes de aceptar su nombramiento en la Corte.

79 Fue senador, embajador, ministro de minas y petróleos del presidente Alfonso López-Pumarejo en 1945, y de relaciones exteriores y de gobierno del gabinete de Mariano Ospina-Pérez (1946).

80 Nariñense. Ya había sido magistrado de la Corte y ministro de gobierno del gabinete de Laureano Gómez (1950). 
ban a la Corte un importante desafío político en la medida en que tocaban intereses del gobierno militar ${ }^{81}$; pero hubo otros que sin alcanzar tal dimensión por tratarse de casos rutinarios, sirvieron para que el tribunal fijara una doctrina deferente con las amplias facultades del Ejecutivo bajo el estado de sitio. De este último grupo hace parte la decisión que se analiza a continuación.

La sentencia del 10 de agosto de $1954^{82}$ resolvía la demanda que acusaba la inconstitucionalidad del Decreto Extraordinario 2460 bis del 13 de octubre de 1952, dictado durante el gobierno del presidente conservador Laureano Gómez. Para comprender el proceso seguido en la Corte, es fundamental recordar estos antecedentes del decreto: la Ley 57 de $1946^{83}$ ordenó un plan de obras para la IX Conferencia Internacional Americana que dio lugar a la creación de la OEA y se celebró en Bogotá entre marzo y abril de 1948 y autorizaba al gobierno nacional a expropiar y declarar la utilidad pública sobre los predios que se requirieran para la ampliación, pavimentación y arborización del "Paseo de los Libertadores", en la capital del país. En cumplimiento del mandato legal, el gobierno dictó el Decreto Ejecutivo 1659 del 14 de agosto de 1951, que declaró la respectiva utilidad pública y dispuso que en caso de que no fuere posible un arreglo con el propietario correspondiente se procedería a la "expropiación, de acuerdo con las leyes de la materia". Luego, al amparo del estado de sitio, el gobierno cambió las reglas de juego en el Decreto extraordinario 2460 bis de 1952 y determinó que el valor de las zonas declaradas de utilidad pública por el decreto 1659 sería el correspondiente al avalúo catastral de los predios con fecha 14 de agosto de 1951.

En criterio del demandante, el decreto 2460 bis de 1952 vulneraba varios artículos de la Constitución porque: (i) excluía a los propietarios de la fijación del precio de los inmuebles expropiados; (ii) imponía la retroactividad a una ley que afectaba la propiedad

81 Un análisis de la jurisprudencia de la Corte en tiempos del gobierno militar, en: MARio Alberto CAJAS-SARria, La historia de la Corte Suprema de Justicia de Colombia, 1886-1991.

82 Colombia, Corte Suprema de Justicia, Sentencia de 10 de agosto de 1954, magistrado ponente Néstor Pineda, abril de 1954, Gaceta Judicial, Tomo 77 (1954-1955), 2140.

83 Colombia, Ley 57 de 1946, por la cual se confieren unas autorizaciones al Órgano Ejecutivo y otras al Contralor General de la República, relativas a la organización de la IX Conferencia Internacional Americana, y se adoptan disposiciones relativas a esa Organización, 18 de diciembre de 1946, 26311 Diario Oficial, 21 de diciembre de 1946. Disponible en: http://www.suin-juriscol.gov.co/clp/ contenidos.dll/Leyes/1609768?fn=document-frame.htm $\$ \mathrm{f}=$ templates $\$ 3.0$ 
privada; (iii) establecía una disposición confiscatoria que significaba un grave perjuicio para el propietario pues se le negaba un justo avalúo, y se eliminaba la diferencia entre el valor comercial y el valor catastral de un inmueble ${ }^{84}$. Y por último, consideró que (iv) se quebrantaba el artículo 121 de la Constitución que limitaba las facultades del gobierno bajo el estado de sitio, toda vez que el decreto contenía medidas sobre "urbanismo y transportes suntuarios", que no tenían nada qué ver con la turbación del orden público que se buscaba restablecer con el estado de sitio declarado el 9 de abril de $1948^{85}$.

El Procurador General de la Nación, que por mandato constitucional intervenía en el proceso con un concepto que no era vinculante para la Corte, consideró que la corporación carecía de facultades "para definir [si] una norma legal determinada es o no incompatible con el estado de sitio, porque ese problema traspasa los naturales límites de la misión eminentemente jurídica que le asigna el artículo 214 de la Carta. Y porque siendo el Presidente de la República quien de acuerdo con la Constitución, es el único responsable del orden público, resultaría contradictorio que hubiera alguien con la atribución de juzgar si un ordenamiento legal impide o no el restablecimiento de ese orden..." ${ }^{\prime 86}$.

84 Colombia, Corte Suprema de Justicia, Sentencia de 10 de agosto de 1954, magistrado ponente Néstor Pineda, abril de 1954, Gaceta Judicial, Tomo 77 (1954-1955), 2140, 326.

85 Tras la división del gobernante partido liberal, el partido conservador ganó las elecciones presidenciales con Mariano Ospina-Pérez en 1946. Ospina debió enfrentar la poderosa oposición de los liberales que eran mayoría en el Congreso, las asambleas departamentales, los concejos municipales y la Corte Suprema. En las elecciones legislativas de 1948, triunfaron los sectores liberales dirigidos por Jorge Eliécer Gaitán, quien se convirtió en el jefe único del partido y en un inatajable candidato para la presidencia para el período 1950-1954. Sin embargo, en medio de una creciente violencia política bipartidista que se extendía por todo el país, de la cual el liberalismo culpaba al gobierno y al partido conservador, Gaitán fue asesinado en el centro de Bogotá el 9 de abril de 1948. Su muerte desencadenó la violenta reacción de las masas populares en la capital y en todo el país. Hubo varios días de desórdenes, saqueos, incendios y vandalismo que cobraron numerosas víctimas y daños materiales .A los hechos se les denominó El Bogotazo. Con un pacto con la dirigencia liberal, Ospina logró recuperar el control de la ciudad y neutralizar la violenta reacción popular. Sobre $E l$ Bogotazo, entre otros: ARturo AlAPE, El Bogotazo: memorias del olvido (Editorial Pluma, Bogotá, 1983). Herbert Braun, The Assassination of Gaitán: Pubic Life and Urban Violence in Colombia (University of Wisconsin Press, Madison, Wisconsin, 2003). GonZalo SÁnchez-Gómez, Los días de la revolución: gaitanismo y 9 de abril en provincia (Centro Cultural Jorge Eliécer Gaitán, Bogotá, 1983). RicARdo Arias, Los sucesos del 9 de abril de 1948 como legitimadores de la violencia oficial, 17 Revista Historia Crítica, 39-46 (1998). Disponible en: https://historiacritica.uniandes.edu.co/ view.php/199/1.php

86 Colombia, Corte Suprema de Justicia, Sentencia de 10 de agosto de 1954, magistrado ponente Néstor Pineda, abril de 1954, Gaceta Judicial, Tomo 77 (1954-1955), 2140, 326. 
El 10 de agosto de 1954, con la ponencia del magistrado liberal Néstor Pineda, la Corte declaró la inconstitucionalidad de los artículos 1 y 3 del Decreto 2460 bis de 1952, en la medida en que encontró que esas disposiciones lesionaban la propiedad privada al fijar como precio del inmueble expropiado el valor correspondiente al avalúo catastral ${ }^{87}$. Para justificar su decisión, la corporación empezó por recordar como precedente su sentencia del 4 de noviembre de $1927^{88}$, cuando decidió sobre la demanda de inconstitucionalidad presentada por el abogado Rafael González-Concha en octubre de $1926^{89}$ en contra de varios artículos de la Ley 84 de 192090, "sobre expropiaciones por causa de utilidad pública". Ese fallo de 1927 declaró inexequible el inciso segundo del artículo 2 de la citada ley, que fijaba el avalúo catastral como precio de un predio en caso de expropiación. En ese entonces, la Corte señaló que cuando el legislador fijaba ese precio como "necesario e inmodificable" para apreciar los perjuicios, vulneraba el derecho a la plena indemnización que ordenaba el artículo 31 de la Constitución.

Aunque la Corte no lo menciona en su sentencia de 1954, en aquel fallo de 1927 la corporación recurrió a uno de los intérpretes más autorizados de la Carta Política de 1886 para establecer el modo como debía entenderse el régimen constitucional de la propiedad y la expropiación. Así, citó a José María Samper, quien fue constituyente en 1886, luego magistrado de la Corte en los inicios de la vigencia de la Constitución y además un doctrinante muy influyente. En su fallo, recordó que Samper en su obra Derecho Público Interno de Colombia señalaba dos principios fundamentales de la organización política de la Nación que se expresaban en las reglas sobre protección del derecho a la propiedad privada: "la inviolabilidad del derecho de

87 La Corte estaba integrada por: Néstor Pineda, Roberto Goenaga; Manuel Barrera-Parra, Aníbal Cardozo-Gaitán, Luis Enrique Cuervo, Darío Echandía, Jesús Estrada-Monsalve, José J. Gómez R., José Hernández-Arbeláez, Ricardo Jordán-Jiménez, Luis F. Latorre, Alfonso Márquez-Páez, Eduardo Rodríguez-Piñeres, Domingo Sarasty, Luis Zafra-Morante y Alberto Zuleta-Ángel. Corte Suprema de Justicia, sentencia del 10 de agosto de 1954.

88 Colombia, Corte Suprema de Justicia, Sentencia de 4 de noviembre de 1927, magistrado ponente Luis Felipe Rosales, Gaceta Judicial, 3 de febrero de 1928, Tomo 34 (1929), 1761-1762.

89 Era hijo del profesor de derecho civil José María González Valencia, de la Universidad Nacional de Colombia y sobrino del expresidente conservador José Vicente Concha [7 de agosto de 1914-7 de agosto de 1918].

90 Colombia, Ley 84 de 1920, sobre expropiaciones por causa de utilidad pública, 17418 Diario Oficial, 18 de noviembre de 1920. Disponible en: http://www.suin-juriscol.gov.co/viewDocument. asp?id=1628047 
propiedad, y su transformación en caso de conflicto con el interés público, por su equivalente exacto en dinero, pagado previamente". De este modo, decía el tribunal, Samper entendía que: "el interés público no impone al ciudadano el sacrificio de su derecho" sino que le imponía un "cambio en la forma: en vez del objeto que el Estado reclama en provecho del interés común, indemniza al propietario su valor, es decir se lo devuelve en otra forma"91.

Luego de recurrir a la autoridad de José María Samper, la Corte de 1927 determinó que la Ley 84 de 1920 vulneraba la Constitución al ordenar que los perjuicios en una expropiación no podían tasarse en una proporción mayor del 20 o del 50 por ciento del avalúo catastral del predio, limitando así la libertad de los peritos del respectivo avalúo mediante el cual se fijaba el valor del pago de la indemnización en favor del propietario. En este sentido, la Corte distinguió entre la estimación de la propiedad para el avalúo de un impuesto, en el entendido de que este "no resulte opresivo ni opresor de la riqueza"; mientras que en el caso de la indemnización por expropiación por motivos de utilidad pública, se trataba de "que la finca expropiada se transforme para su dueño en un valor equivalente y exacto en dinero, tal como lo tendría de acuerdo con las condiciones con que se fija el precio comercial de las cosas" ${ }^{\prime 2}$.

Regresando a la sentencia de 1954, como se dijo atrás, la decisión se fundaba en parte en el precedente fijado por el fallo de 1927, pues la corporación entendía que el decreto 2460 bis de 1952 era inconstitucional porque fijaba el precio de los predios a expropiar según el avalúo catastral y no el avalúo comercial ${ }^{93}$. Esto dijo la Corte:

De acuerdo con la sentencia de que se acaba de hablar, es inexequible por violatoria de la Constitución la norma legal que imponga el avalúo catastral como necesario e invariable, como el valor preestablecido o equivalente de la indemnización, a que, por garantía constitucional, tiene derecho el propietario

91 Colombia, Corte Suprema de Justicia, Sentencia de 4 de noviembre de 1927, magistrado ponente Luis Felipe Rosales, Gaceta Judicial, 3 de febrero de 1928, Tomo 34 (1929), 1761-1762, 113.

92 Colombia, Corte Suprema de Justicia, Sentencia de 4 de noviembre de 1927, magistrado ponente Luis Felipe Rosales, Gaceta Judicial, 3 de febrero de 1928, Tomo 34 (1929), 1761-1762, 114.

93 Esta sentencia luego hizo parte del precedente citado por la Corte para determinar los alcances de las reglas sobre expropiación. Por ejemplo, en la Sentencia 5 del 1 de febrero de 1990, que declaró inexequibles algunos artículos de la Ley 9 de 1989. Colombia, Corte Suprema de Justicia, Sentencia 5, 1 de febrero de 1990, magistrados ponentes Hernando Gómez-Otálora y Jaime Sanín-Greiffenstein, Gaceta Judicial, Tomo 201, primer semestre de 1990, 2440. 
cuando por motivos de utilidad pública el interés privado deba ceder al interés público o social. El punto, fue, pues, resuelto en forma definitiva por la Corte.

Pero la Corte de 1954 no solo tuvo en cuenta su precedente de 1927, que aludía al régimen constitucional de la expropiación según Samper, sino que recurrió al pensamiento de Miguel Antonio Caro, padre fundador de la Constitución de 1886 y de la Regeneración, para interpretar los significados atribuibles a las cláusulas constitucionales sobre la propiedad y la expropiación. Dijo la corporación:

El señor Caro, intérprete autorizado de la Constitución, decía que "el principio constitucional de la expropiación legítima se desenvuelve así: admítese en primer lugar el derecho de propiedad, como derecho natural. Vienen luego las excepciones a esta regla general —contribuciones públicas, multas y apremios y expropiación forzosa - excepciones fundadas en este otro principio de derecho: que en caso de conflicto entre el interés público y el interés privado prevalece el interés público. Este principio limita el primero; pero a fin de evitar abusos en sus aplicaciones, se establecen en tercer lugar, para llevar a cabo la expropiación, ciertas formas protectoras que aseguran la equidad y justica del procedimiento. Las leyes de expropiación o enajenación forzosa reconocen y acatan en cierto modo el derecho de propiedad como distinto del valor de la cosa que se expropia. El propietario, según estas leyes, solo puede ser privado de su propiedad por causa de utilidad pública, pero esta debe ser legalmente justificada, y el propietario ha de ser satisfecho, no solo del valor de la cosa, sino también de los daños que se le sigan (...) La expropiación resuelve un conflicto entre el interés privado y el público; acto grave y delicado, que la necesidad y la debida indemnización justifican y que no debe ejecutarse sin llenar todas las formas que protegen al derecho individual contra los abusos"94.

Así las cosas, la Corte de 1954 recurría de manera indirecta, por la vía de la sentencia de 1927, y de manera directa en el fallo de 1954, a los dos intérpretes más autorizados de la Constitución de 1886: Samper y Caro ${ }^{95}$. Estos constituyentes y juristas representaban posturas doctrinales opuestas en distintos aspectos fundamentales de la Carta Política, siete décadas atrás; pero según la jurisprudencia de la Corte coincidían en que la prevalencia del derecho a

94 Colombia, Corte Suprema de Justicia, Sentencia de 10 de agosto de 1954, magistrado ponente Néstor Pineda, abril de 1954, Gaceta Judicial, Tomo 77 (1954-1955), 2140, 329.

95 Para un análisis sobre las tensiones entre el ideario de Caro y Samper con respecto a la Constitución de 1886, incluyendo el derecho de propiedad: JoRge GonzÁLEZ-JÁCOME, Los debates del pensamiento jurídico colombiano entre 1886 y 1920, 98-118 (Universidad Javeriana, Depalma \& Ibáñez, Bogotá, 2011). 
la propiedad privada y la necesidad de indemnizar plenamente a quien sufría una expropiación por razones de utilidad pública, eran elementos centrales de la Constitución ${ }^{96}$.

De igual modo, la Corte encontró que el decreto demandado afectaba el debido proceso pues establecía que, cuando un propietario acudiera a un juez en ejercicio de sus acciones indemnizatorias, este solo tendría en cuenta el valor de su inmueble según el avalúo catastral: "La expropiación de la propiedad privada se valida en cuanto no signifique una transgresión de la regla del debido procedimiento legal, que constituye una garantía sustantiva de la libertad civil, y esta exige que la limitación impuesta por la ley a los derechos individuales sea razonable en vista del fin que forma su objeto". También consideró que el decreto vulneraba el "principio de igualdad ante la ley" porque fijaba una regla para la expropiación que solo era aplicable a los propietarios de los predios necesarios para la ampliación, pavimentación y arborización del "Paseo de los Libertadores" mientras que las demás expropiaciones se regían por las leyes generales sobre la materia, que sí establecían una justa y plena indemnización de conformidad con la Constitución.

La corporación también señaló que la Constitución le fijaba al ejecutivo unas reglas expresas para afectar el derecho a la propiedad privada. Así, en tiempos de paz solo procedía la expropiación por sentencia judicial e indemnización previa; o sin indemnización para el caso de una declaratoria de utilidad pública aprobada por mayoría absoluta del Congreso, mientras que en el caso de guerra solo podía haber ocupación temporal del inmueble pero nunca una expropiación sin indemnización. Con base en este análisis, consideró que el decreto demandado sometía a la propiedad privada, durante el estado de sitio, a reglamentaciones y limitaciones diferentes a las prescritas por la Constitución, pues el gobierno no tenía "más facultades para limitar el contenido y el ejercicio de la propiedad que las previstas en el texto constitucional que contem-

96 Como bien lo pone de presente Jorge González, Samper no tenía una concepción tan “neutral” sobre las indemnizaciones. Aun cuando la Constitución no distinguía entre quienes podían exigir indemnizaciones en caso de guerra, Samper pensaba que el Estado no tenía la obligación de indemnizar a quienes no eran leales al régimen constitucional. Por eso entendía que la Constitución dejaba gran discrecionalidad a autoridades no judiciales para expropiar sin indemnización. JoRGE GONZÁLEZJÁcome, Los debates del pensamiento jurídico colombiano entre 1886 y 1920, 85 (Universidad Javeriana, Depalma \& Ibáñez, Bogotá, 2011). 
pla el estado de guerra" ${ }^{97}$. En suma, que la Carta Política limitaba los poderes legislativos del gobierno en los casos de afectación del "contenido y el ejercicio del derecho de propiedad" en la hipótesis del estado de guerra, que debían entenderse como aplicables al caso de la turbación del orden público interno, es decir, al estado de sitio.

Por último, la Corte expresó que no era del caso estudiar otros cargos de la demanda ni tampoco el concepto del Procurador General de la Nación que se referían al alcance y las limitaciones de las facultades del gobierno durante la turbación del orden público, "porque las razones expuestas hasta aquí son suficientes para declarar, como en efecto habrá de declararse, que son inexequibles las disposiciones acusadas".

Los magistrados liberales Darío Echandía y Néstor Pineda salvaron su voto y dejaron constancia de que la sentencia había quedado incompleta. Manifestaron que el proyecto de fallo que había elaborado Pineda contenía un estudio del régimen del estado de sitio, pero que este fue rechazado por el pleno de la Corte al considerar que ya había "suficiente fundamento" para decidir.

Contrario a la postura de la Sala Plena, ambos magistrados insistieron en que la Corte debió haber reafirmado su competencia para fijar límites a los decretos de estado de sitio que dictaba el Ejecutivo; así mismo, que era inaceptable que tales decretos, por el solo hecho de ser dictados por el gobierno, gozaran de un sello de legitimidad, dado que el propósito de la Constitución era: "impedir la posibilidad de un exceso o desviación de los poderes presidenciales en estado de sitio, que ponga los decretos del Gobierno en conflicto con las normas constitucionales" $"$.

En criterio de los magistrados disidentes, cuando el gobierno declaraba turbado el orden público lo hacía con la finalidad de contar con medios de acción más rápidos y eficaces que aquellos "que lícitamente puede usar en el estado normal del derecho", y así cumplir el fin primordial de mantener en todo el territorio el orden, así como restablecerlo cuando y donde fuere turbado. De este modo, si bien le reconocían al Ejecutivo una amplia esfera de

97 Colombia, Corte Suprema de Justicia, Sentencia de 10 de agosto de 1954, magistrado ponente Néstor Pineda, abril de 1954, Gaceta Judicial, Tomo 77 (1954-1955), 2140, 328.

98 Colombia, Corte Suprema de Justicia, Sentencia de 10 de agosto de 1954, magistrado ponente Néstor Pineda, salvamento de voto de los magistrados Darío Echandía y Néstor Pineda, Gaceta Judicial, Tomo 77 (1954-1955), 2140, 332. 
actuación, su límite era el fin y el objetivo concreto de esas facultades que la Constitución le concedía; que se expresaban por medio de los decretos extraordinarios. Por tanto, si aquellas medidas no tenían "relación alguna, lógica, ni real con dicho fin, ellos deben ser declarados inexequibles".

Para defender su argumento de que el gobierno tenía límites para actuar bajo el estado de sitio, ahondaron en la concepción de los fines del Estado, de la Constitución y de los poderes públicos. En su opinión, el Estado perseguía con toda su actividad unos objetivos determinados, que se ataban en últimas a un "concepto de los valores sociales"; y que por tanto el Constituyente y el Legislador no podían obrar "sin designio preconcebido". El sistema jurídico, además, debía inspirarse en un concepto del bien común, es decir: "en una idea acerca del conjunto de condiciones sociales que son necesarias para que el hombre pueda cumplir un destino material y espiritual".

Esa concepción del ordenamiento jurídico, dijeron, era la misma del jurista francés François Gény, padre de la libre investigación científica $^{99}$, para quien una organización jurídica ${ }^{100}$ : "tiene como fin buscar el equilibrio de los intereses opuestos. Su objeto, en efecto, no es otro que dar una más adecuada satisfacción a las diversas aspiraciones rivales, cuya justa conciliación parezca necesaria para realizar el fin social de la especie humana. El medio general de obtener tal resultado consiste en reconocer los intereses opuestos, valorar su fuerza respectiva, pesarlos en cierto modo en una balanza de la justicia para asegurar el predominio de los más importantes, según el criterio social y, finalmente establecer entre ellos el equilibrio deseado"101.

99 ANDRÉS Botero-BERnAL, El positivismo jurídico en la historia: las escuelas del positivismo jurídico en el siglo XIX y primera mitad del siglo XX, en Enciclopedia de filosofía y teoría del derecho, 63-170, (Jorge Luis FABRA, ed., Instituto de Investigaciones Jurídicas de la UNAM, México, 2015). Disponible en: https://archivos.juridicas.unam.mx/www/bjv/libros/8/3875/6.pdf. MARÍA José BERnUZBeneitez, François Gény y el derecho: la lucha contra el método exegético (Universidad Externado de Colombia, Bogotá, 2006); y también CARLos PetIT, "A Contributor to the Method of Investigation". sobre la fortuna de Gény en América, 20 Quaderni Fiorentini per la storia del pensiero giuridico moderno, 1, 201-271 (1991). Disponible en: http://www.centropgm.unifi.it/quaderni/20/index.htm

100 Colombia, Corte Suprema de Justicia, Sentencia de 10 de agosto de 1954, magistrado ponente Néstor Pineda, salvamento de voto de los magistrados Darío Echandía y Néstor Pineda, Gaceta Judicial, Tomo 77 (1954-1955), 2140, 332.

101 Según Diego López, con los "principios", Gény buscaba renovar el derecho privado en clave antiformalista. Esos principios se inducían "de las consideraciones morales, políticas, sociales y económicas" de la época; dado su tono abiertamente político y moral, empujaban al derecho "hacia 
De acuerdo con esta concepción, los magistrados estimaban que la Constitución era un conjunto de normas tendientes a realizar los fines del "ordenamiento positivo". De ahí se seguía que la interpretación de la Constitución debía hacerse: "siempre en relación con esos fines últimos y superiores". Como aun en tiempos de perturbación del orden público la norma constitucional debía entenderse como un principio para organizar en lugar de "disolver" o "anarquizar", controvirtieron la tesis del procurador según la cual la Corte carecía de competencia para juzgar si un decreto del Ejecutivo era conducente para restablecer el orden público. De acogerse tal tesis, el gobierno podría declarar turbado el orden público para eliminar todas las garantías y libertades constitucionales, y "destruir la totalidad del ordenamiento jurídico"102.

Por todo esto afirmaron que la Corte debió mantener la doctrina que había fijado en las sentencias del 12 de junio de 1945 y del 9 de julio de 1948, según la cual el poder Ejecutivo estaba limitado por el orden constitucional cuando tomaba medidas dentro del régimen del estado de sitio; y que estas debían ceñirse a la finalidad del restablecimiento del orden público. Esta doctrina, dijeron: "es la acorde con los textos de nuestra Carta Política fundamental y con los principios universales que informan el derecho público de los estados democráticos".

Como se puede notar, este salvamento insistía en la necesidad de que la Corte mantuviera su línea de fijar límites a las facultades del Ejecutivo bajo el estado de sitio, pero la mayoría en la corporación prefirió otro camino, precisamente cuando el general Gustavo Rojas Pinilla gobernaba mediante decretos de estado de sitio.

\footnotetext{
una posición más equilibrada en el conflicto político entre las clases sociales que se presentaba como fruto de la llamada 'cuestión social'. Esta nueva comprensión de los principios buscó alejar el conjunto del derecho civil del fundamentalismo liberal del siglo XIX y permearlo con una comprensión más moral y social". Gény entendía los principios jurídicos como aquellos que se expresan en términos de conveniencia basados en el estudio empírico de la realidad, pero también como "fines, finalidades o propósitos". Bajo esta segunda concepción, López propone que, para Gény, los principios-fines son "entidades normativas superiores a las reglas, de naturaleza hipotética y no definitiva o dogmática, basados en la observación informal de los intereses sociales y en los que se busca un equilibrio moral satisfactorio para el cuerpo social". Diego Eduardo LóPEZ-Medina, Teoría impura del derecho: la transformación de la cultura jurídica latinoamericana, 276-278 (Legis, Universidad de los Andes y Universidad Nacional, Bogotá, 2004).

102 Acogen entonces la segunda de las concepciones sobre los principios que propone Gény: los principios-fines. Así, las normas constitucionales se interpretaban según unas finalidades u objetivos, y estas contenían principios.
} 
Por otra parte, no se debe descartar que la voz de los magistrados liberales Pineda y Echandía haya sido un síntoma de la distancia que empezaba a separar a sectores importantes de la dirigencia del partido liberal y el gobierno de Rojas, o que al menos haya sido una señal de advertencia sobre los riesgos del gran poder que empezaba a acumular el régimen militar. En ese sentido, se debe recordar que un mes antes del fallo, Rojas había reintegrado la Asamblea Nacional Constituyente (ANAC) con miembros leales al gobierno; y que ese órgano presidido por el expresidente conservador Mariano Ospina-Pérez había reelegido a Rojas para el período presidencial 1954-1958, con lo cual poco a poco empezaban a resquebrajarse sus relaciones con el liberalismo. Por último, en marzo de 1954, Echandía habría asistido a alguna de las reuniones promovidas por el dirigente liberal Alfonso López-Pumarejo ${ }^{103}$, quien pensaba en un plan para sacar a Rojas del poder e insistía en que los liberales no deberían colaborar con el gobierno militar.

Otro magistrado liberal también salvó su voto. Eduardo Rodríguez-Piñeres defendió con vehemencia la competencia de la Corte para juzgar la constitucionalidad de los decretos de estado de sitio, y reaccionó a la tesis del Procurador según la cual ese tribunal no podía ejercer tal control: "al admitirse tal concepto como ajustado a la Constitución, se desconocía esta y se cumpliría en Colombia el anatema consignado por el artículo 16 de la Declaración de los Derechos del Hombre y el Ciudadano proclamado por la Asamblea Constituyente de Francia conforme al cual 'toda sociedad en la cual la garantía de los derechos no está asegurada, ni la separación de poderes determinada, no tiene Constitución"'104. Por último, consideró que el Ejecutivo había extralimitado sus facultades constitucionales al dictar un decreto que no tenía nada qué ver con el restablecimiento del orden público ni con el estado de sitio que regía en el país.

103 Jorge Gartner de la Cuesta, Mis memorias, o devaneos inútiles de un desocupado, 319-320 (Imprenta Departamental de Caldas, Manizales, 1991), citado por JAmes D. Henderson, La modernización en Colombia: los años de Laureano Gómez, 1889-1965, 544 (Universidad de Antioquia, Medellín, 2006).

104 Colombia, Corte Suprema de Justicia, Sentencia de 10 de agosto de 1954, magistrado ponente Néstor Pineda, salvamento de voto del magistrado Eduardo Rodríguez-Piñeres, Gaceta Judicial, Tomo 77 (1954-1955), 2140, 337. 
Así las cosas, en esta sentencia de 1954 la Corte asumió la competencia para juzgar la constitucionalidad del decreto demandado, pero prefirió centrarse en analizar si este vulneraba normas constitucionales sobre la propiedad privada, la expropiación, la igualdad y el debido proceso, de modo que no tocó el asunto de las facultades presidenciales bajo el estado de sitio. La corporación parecía actuar con deferencia ante el gobierno militar, tal vez midiendo los posibles efectos de una decisión que podría recordarle al general Rojas que sus actuaciones dentro del estado de excepción estaban sujetas al control de constitucionalidad del tribunal. Esta abstención, a su vez, le evitaba a la Corte tener que evaluar si los decretos extraordinarios dictados desde que se declaró el estado de sitio en 1948, guardaban o no relación con los fines de ese estado de excepción, es decir, con el restablecimiento del orden público turbado.

En suma, si bien en este caso la Corte declaró inexequible un decreto sobre un asunto que parecía puramente rutinario y que no produjo tensiones con el gobierno del general Rojas, con el fallo anunciaba que no fijaría límites a las facultades del Ejecutivo bajo el estado de excepción. Así, este comportamiento estratégico de la Corte de 1954 parecía asemejarse al de 1912, cuya postura minimalista permitió proteger la propiedad privada, y al mismo tiempo, evadir el debate constitucional sobre el poder presidencial en el marco del estado de sitio. 


\section{REFLEXIONES FINALES}

Este trabajo ha examinado dos intervenciones de la Corte Suprema de Justicia en momentos de la historia política colombiana bien diferenciados. Uno en 1912, en los inicios de la acción pública de inconstitucionalidad tras la reforma constitucional de 1910, y otro bajo el gobierno militar del general Gustavo Rojas-Pinilla a mediados del siglo XX. En ambos casos, la Corte actuó para defender el derecho a la propiedad privada y los derechos adquiridos de los ciudadanos ante medidas dictadas al amparo del estado de sitio.

Como se dijo al inicio, la literatura académica se ha referido a las graves vulneraciones de los derechos y libertades bajo el régimen de estado de sitio en Colombia buena parte del siglo XX, y ha criticado el déficit de defensa de ellos en la jurisprudencia de la Corte Suprema de Justicia. Con el fin de avanzar en otro tipo de exploraciones que permitan dar cuenta más detallada del comportamiento del tribunal bajo el régimen de excepción, se han examinado dos fallos que ilustran cómo la corporación intervino para proteger el derecho a la propiedad privada y los derechos adquiridos frente a los excesos del Ejecutivo.

Las dos sentencias examinadas ponen de presente que la Corte en dos momentos políticos diferentes prefirió un comportamiento estratégico; evadió el debate sobre los límites constitucionales a las facultades del Ejecutivo bajo el estado de sitio para concentrarse en el juicio de si las medidas demandadas vulneraban el derecho a la propiedad privada y los derechos adquiridos de los particulares. De este modo, la comparación no solo da cuenta de las doctrinas de la Corte sino también de las tensiones políticas y las relaciones entre las ramas judicial y ejecutiva en esas coyunturas.

Este estudio, a su vez, deja abiertas posibles líneas de trabajo que no han sido desarrolladas de manera suficiente en Colombia. Por ejemplo, la historia jurídica de la propiedad privada y la expropiación; o la historia del derecho en los gobiernos de Rafael Reyes y Gustavo Rojas-Pinilla.

Por último, este tipo de intervenciones de la Corte Suprema de Justicia en contextos políticos diferentes sugiere nuevas rutas para analizar el papel de la justicia constitucional en la historia colombiana; explorar las interdependencias entre la doctrina legal y la 
política, y para avanzar en estudios comparados sobre la historia judicial en la región. 


\section{BIBLIOGRAFÍA}

\section{Libros}

Alape, Arturo, El Bogotazo: memorias del olvido (Editorial Pluma, Bogotá, 1983).

Barreto-Rozo, Antonio, La generación del estado de sitio, el juicio de anormalidad institucional de la Asamblea Nacional Constituyente de 1991 (Universidad de los Andes, Bogotá, 2012).

Barreto-Rozo, Antonio, Venturas y desventuras de la Regeneración: apuntes de historia jurídica sobre el proyecto político de 1886 y sus transformaciones y rupturas en el siglo $X X$ (Universidad de los Andes, Bogotá, 2011).

Bergquist, Charles W., Café y conflicto en Colombia, 1886-1910: la guerra de los Mil Días: sus antecedentes y consecuencias (Fundación Antioqueña de Estudios Sociales, FAES, Medellín, 1981).

Bernuz-Beneitez, María José, François Gény y el derecho: la lucha contra el método exegético (Universidad Externado de Colombia, Bogotá, 2006)

Braun, Herbert, The Assassination of Gaitán: Pubic Life and Urban Violence in Colombia (University of Wisconsin Press, Madison, Wisconsin, 2003).

Cajas-Sarria, Mario Alberto, La historia de la Corte Suprema de Justicia de Colombia, 1886-1991, 2 tomos (Universidad de los Andes, Universidad Icesi, Bogotá, 2015).

Chacón y Barrios, Jacinto, Exposición razonada y estudio comparativo del Código Civil Chileno (Imprenta del Mercurio, Valparaíso, 1868).

Correa-Uribe, Fernando, Republicanismo y reforma constitucional (Facultad de Ciencias Sociales y Humanas, Universidad de Antioquia, Medellín, 1996).

Crowe, Justin, Building the Judiciary: Law, Courts, and the Politics of Institutional Development (Princeton University Press, Princeton, New Jersey, 2012).

Gallón-Giraldo, Gustavo, Quince años de estado de sitio en Colombia, 1958-1978 (Ediciones Guadalupe, Bogotá, 1979).

Gargarella, Roberto, Los fundamentos legales de la desigualdad: el constitucionalismo en América (1776-1860) (Siglo XXI, Buenos Aires, 2010).

Ginsburg, Tom \& Moustafa, Tamir, eds., Rule by Law: The Politics of Courts in Authoritarian Regimes (Cambridge University Press, Cambridge, 2008).

GonzÁlez-JÁcome, Jorge, Estados de excepción y democracia liberal en América del Sur: Argentina, Chile y Colombia, 1930-1990 (Pontificia Universidad Javeriana, Bogotá, 2015).

GonzÁlez-JÁcome, Jorge, Los debates del pensamiento jurídico colombiano entre 1886 y 1920 (Universidad Javeriana, Depalma \& Ibáñez, Bogotá, 2011).

Helmke, Gretchen, Courts under Constraints: Judges, Generals and Presidents in Argentina (Cambridge University Press, Cambridge, 2012).

Henderson, James D., La modernización en Colombia: los años de Laureano Gómez, 1889-1965 (Universidad de Antioquia, Medellín, 2006). 
Hilbink, Lisa, Judges beyond Politics in Democracy and Dictatorship: Lessons from Chile (Cambridge University Press, New York, 2007).

Horwitz, Morton J., The Transformation of American Law, 1870-1960: The Crisis of Legal Orthodoxy (Oxford University Press, Oxford, 1992).

Iturralde, Manuel, Castigo, liberalismo autoritario y justicia penal de excepción (Siglo del Hombre Editores, Bogotá, 2009).

Kahn, Ronald \& Kersch, Ken I., eds., The Supreme Court and American Political Development (University Press of Kansas, Lawrence, Kansas, 2006).

Lemaitre, Eduardo, Rafael Reyes: biografía de un gran colombiano (4⿳亠丷⿵冂丶 ed., Editorial Norma, Bogotá, 1994).

Locke, John, Segundo Tratado sobre el gobierno civil: un ensayo acerca del verdadero origen, alcance y fin del Gobierno Civil (CARLos Mellizo, traducción, prólogo y notas, Alianza, Madrid, 1990).

López-Medina, Diego Eduardo, Teoría impura del derecho: la transformación de la cultura jurídica latinoamericana (Legis, Universidad de los Andes y Universidad Nacional, Bogotá, 2004).

Mozos, José LuIS DE Los, El derecho de propiedad: crisis y retorno a la tradición jurídica (Editorial Revista de Derecho Privado, Editoriales de Derecho Reunidas, Madrid, 1993).

Palacios, Marco, Entre la legitimidad y la violencia: Colombia, 1875-1994 (2ª ed., Norma, Colección Vitral, Bogotá, 2004).

Palau, Lisímaco, Colombia en 1907 bajo la administración del Sr. General Rafael Reyes (Imprenta Nacional, Bogotá, 1907). Disponible en: http://banrepcultural.org/ sites/default/files/87747/brblaa146761.pdf

Restrepo-Piedrahita, Carlos, comp., Constituciones Politicas Nacionales de Colombia ( $3^{a}$ ed., Universidad Externado de Colombia, Bogotá, 2003).

SÁnchez-Gómez, Gonzalo, Los días de la revolución: gaitanismo y 9 de abril en provincia (Centro Cultural Jorge Eliécer Gaitán, Bogotá, 1983).

Tirado-Mejía, Álvaro, Aspectos políticos del primer gobierno de Alfonso López Pumarejo, 1934-1938 (Planeta, Bogotá, 1995).

Tirado-Mejía, Álvaro \& Velásquez, Magdala, La reforma constitucional de 1936 (Fundación Friederich Naumann, Oveja Negra, Bogotá, 1982).

Valencia-Villa, Hernando, Cartas de batalla: una crítica del constitucionalismo colombiano (Universidad Nacional de Colombia, CEREC, Bogotá, 1987).

Vélez, Fernando, Estudio sobre el Derecho Civil colombiano (Imprenta Nacional, Medellín, 1909).

Vera, Robustiano, Código Civil de la República de Chile, comentado y explicado (Imprenta Nacional, Santiago de Chile, 1892-1897). 


\section{Colaboración en obras colectivas}

Botero-Bernal, ANDRÉs, El positivismo jurídico en la historia: las escuelas del positivismo jurídico en el siglo XIX y primera mitad del siglo XX, en Enciclopedia de filosofía y teoría del derecho, 63-170 (JoRGE LuIS FABRA, ed., Instituto de Investigaciones Jurídicas de la UNAM, México, 2015). Disponible en: https://archivos.juridicas. unam.mx/www/bjv/libros/8/3875/6.pdf

García-Villegas, Mauricio, Constitucionalismo perverso, normalidad y anormalidad constitucionalidad en Colombia, 1957-1997, en El caleidoscopio de las justicias en Colombia: análisis socio-jurídico, Tomo I, 317-370 (Boaventura De SousaSantos \& Mauricio García-Villegas, eds., Colciencias, Instituto Colombiano de Antropología e Historia, ICANH, Universidad de los Andes, Siglo del Hombre, Bogotá, 2001).

Melo, Jorge Orlando, La Constitución de 1886, en Nueva Historia de Colombia, Tomo 1, Historia Política 1886-1946, 43-64 (Álvvaro Tirado-Mejía, ed., Planeta, Bogotá, 1989).

Melo, Jorge Orlando, Núñez y la Constitución de 1886: triunfo y fracaso de un reformador, en Núñez y Caro 1886 (Banco de la República, Bogotá, 1986). Disponible en: http://www.jorgeorlandomelo.com/nunez.htm

Restrepo-Piedrahita, Carlos, Constitución Politica de la República de Colombia de 1886, en Constituciones Politicas Nacionales de Colombia, 341-590 ( $3^{\mathrm{a}}$ ed., CARlos Restrepo-Piedrahita, comp., Universidad Externado de Colombia, Bogotá, 2003).

Tirado-Mejía, Álvaro, López Pumarejo, la Revolución en Marcha, en Nueva Historia de Colombia, Vol. I, Historia Politica 1886-1946, 305-348 (Álvaro Tirado-Mejía, coord., Planeta, Bogotá, 1989).

Vélez-Ramírez, Humberto, Rafael Reyes: Quinquenio, régimen político y capitalismo, 1904-1909, en Nueva Historia de Colombia, Tomo I, 187-214 (Editorial Planeta, Bogotá, 1989).

\section{Revistas}

Arias, Ricardo, Los sucesos del 9 de abril de 1948 como legitimadores de la violencia oficial, 17 Revista Historia Crítica, 39-46 (1998). Disponible en: https:// historiacritica.uniandes.edu.co/view.php/199/1.php

Botero, SANDra, La reforma constitucional de 1936, el Estado y las politicas sociales en Colombia, 33 Anuario Colombiano de Historia Social y de la Cultura, ACHSC, 85109 (2006). Disponible en: http://www.bdigital.unal.edu.co/14332/1/3-8216-PB.pdf

Botero-Bernal, Andrés, Haciendo memoria de la defensa judicial de la Constitución, 20 Pensamiento Jurídico, 91-102 (2007). Disponible en: http://www.revistas.unal. edu.co/index.php/peju/article/view/38627/pdf_239

Cajas-Sarria, Mario Alberto, La Corte Suprema de Justicia bajo el gobierno del general Gustavo Rojas Pinilla, 50 Revista de Estudios Sociales, 127-139 (2014). Disponible en: https://res.uniandes.edu.co/view.php/943/index.php?id=943 
Cajas-Sarria, Mario Alberto, La Corte Suprema de Justicia de Colombia, 1886-1910: de juez de la Regeneración a juez constitucional, 14 Historia Constitucional, 425465 (2013). Disponible en: http://www.historiaconstitucional.com/index.php/ historiaconstitucional/article/view/378/341

Cajas-Sarria, Mario Alberto, la justicia constitucional del general Gustavo Rojas Pinilla: entre el Tribunal de Garantías Constitucionales y la Sala de Negocios Constitucionales, Colombia, 1953-1957, 17 Revista de Historia Constitucional, 273-307 (2016). Disponible en: http://www.historiaconstitucional.com/index. $\mathrm{php} / \mathrm{historiaconstitucional/article/view/464/421}$

Díaz, Sylvia Beatriz, Finanzas públicas del gobierno central en Colombia, 1905-1925, 14 Historia Crítica, 59-80 (1997). Disponible en: https://historiacritica.uniandes. edu.co/view.php/465/index.php?id=465

Hernández-Becerra, Augusto, La revocatoria del Congreso en 1905, 162 Credencial Historia (2003). Disponible en: http://www.banrepcultural.org/revista-59

Malagón-Pinzón, Miguel, La Regeneración, la Constitución de 1886 y el papel de la Iglesia Católica, 11 Civilizar, Ciencias Sociales y Humanas (2006). Disponible en: http://repository.usergioarboleda.edu.co/bitstream/handle/11232/336/ CienciasSocialesyHumanas6117.pdf?sequence $=1$

Marquardt, Bernd, Estado y Constitución en la Colombia de la Regeneración del Partido Nacional, 1886-1909, 6 Ciencia Política, 11, 56-81 (2011). Disponible en: http:// www.revistas.unal.edu.co/index.php/cienciapol/article/view/41501/43115

Petit, CARlos, "A Contributor to the Method of Investigation": sobre la fortuna de Gény en América, 20 Quaderni Fiorentini per la storia del pensiero giuridico moderno, 1, 201271 (1991). Disponible en: http://www.centropgm.unifi.it/quaderni/20/index.htm

Randall, Stephen J., Nationbuilding and Civil War: Diverging Views of State and Society in Late 19 ${ }^{\text {th }}$ Century Colombia, 16 Journal of Military and Strategic Studies, 3, 92-114 (2015). Disponible en: http://jmss.org/jmss/index.php/jmss/article/ download/627/596

Vélez-Ramírez, Humberto, Rafael Reyes, o los inicios del Estado moderno en Colombia, 21 Lecturas de Economía, 59-80 (1986). Disponible en: https://aprendeenlinea. udea.edu.co/revistas/index.php/lecturasdeeconomia/article/view/7951/7453

\section{Documentos y tesis}

Junguito, Roberto \& Rincón, Hernán, La política fiscal en el siglo XX en Colombia, Documento preparado para el seminario Investigaciones recientes sobre historia económica colombiana, 4 y 5 de agosto de 2004, Bogotá. Disponible en: https:// core.ac.uk/download/pdf/7077619.pdf?repositoryId=153

Romero-Moreno, Rodrigo, Dos dictaduras colombianas: un análisis sobre nacionalismo e identidad nacional, tesis de la Maestría en Historia, Universidad Industrial de Santander, Bucaramanga (2007). Disponible en: http://repositorio.uis.edu.co/ jspui/bitstream/123456789/9846/2/124934.pdf 


\section{Normatividad colombiana}

Colombia, Acto reformatorio 1 de 1905, por el cual se reforman los artículos 147 y 155 de la Constitución de la República, 27 de marzo de 1905, 12314 Diario Oficial, 30 de marzo de 1905. Disponible en: http://www.suin.gov.co/viewDocument. asp?id=1824849

Colombia, Acto legislativo 06 de 1905, por el cual se sustituye el artículo 32 de la Constitución Nacional, 12323 Diario Oficial, 10 de abril de 1905. Disponible en: http://www.suin-juriscol.gov.co/viewDocument.asp?id=1000200

Colombia, Acto legislativo 03 de 1910, reformatorio de la Constitución Nacional, 31 de octubre de 1910, 14131 Diario Oficial, 31 de octubre de 1910. Disponible en: http://suin-juriscol.gov.co/viewDocument.asp?id=1825559

Colombia, Acto Legislativo 01 de 1936, reformatorio de la Constitución, 5 de agosto de 1936, 23263 Diario Oficial, 22 de agosto de 1936. Disponible en: http://www. suin-juriscol.gov.co/viewDocument.asp?id=1824914

Colombia, Constitución Política de 1886, 5 de agosto de 1886. Disponible en: http:// www.alcaldiabogota.gov.co/sisjur/normas/Norma1.jsp?i=7153

Colombia, Decreto legislativo 29 de 1905, 1 de febrero de 1905.

Colombia, Decreto legislativo 40 de 1905, sobre desecación de lagunas, ciénagas y pantanos, 28 de febrero de 1905 .

Colombia, Decreto legislativo 3110 de 1953, por el cual se acepta la renuncia de la Corte Suprema de Justicia y se designa en interinidad nueva Corte, 27 de noviembre de 1953, 28359 Diario Oficial, 30 de noviembre de 1953.

Colombia, Ley 84 de 1873, Código Civil de los Estados Unidos de Colombia, 26 de mayo de 1873, 2867 Diario Oficial, 31 de mayo de 1873. Disponible en: http://www. suin-juriscol.gov.co/viewDocument.asp?ruta=Leyes/1827111

Colombia, Ley 57 de 1887, sobre adopción de códigos y unificación de la legislación nacional, 15 de abril de 1887, 7019 Diario Oficial, 20 de abril de 1887. Disponible en: http://www.secretariasenado.gov.co/senado/basedoc/codigo_civil.html, http://www.alcaldiabogota.gov.co/sisjur/normas/Norma1.jsp?i=39535

Colombia, Ley 153 de 1887, por la cual se adiciona y reforma los códigos nacionales, la Ley 61 de 1886 y la 57 de 1887, 7151 y 7152 Diario Oficial, 28 de agosto de 1887. Disponible en: http://www.alcaldiabogota.gov.co/sisjur/normas/Normal. jsp?i=15805

Colombia, Ley 6 de 1905, por el cual se ratifican algunos Decretos de carácter legislativo que han tenido origen en el Ministerio de Obras Públicas, 12323 Diario Oficial, 10 de abril de 1905. Disponible en: http://www.suin-juriscol.gov.co/viewDocument. asp?id=1695117

Colombia, Ley 8 de 1905, por la cual se aprueban varios Decretos de carácter legislativo dictados por el órgano del Ministerio de Gobierno, 5 de abril de 1905, 12323 Diario Oficial, 10 de abril de 1905. Disponible en: http://www.suin-juriscol.gov. co/viewDocument.asp?id=1821142

Colombia, Ley 84 de 1920, sobre expropiaciones por causa de utilidad pública, 17418 Diario Oficial, 18 de noviembre de 1920. Disponible en: http://www.suin-juriscol. 
gov.co/viewDocument.asp?id=1628047

Colombia, Ley 57 de 1946, por la cual se confieren unas autorizaciones al Órgano Ejecutivo y otras al Contralor General de la República, relativas a la organización de la IX Conferencia Internacional Americana, y se adoptan disposiciones relativas a esa Organización, 18 de diciembre de 1946, 26311 Diario Oficial, 21 de diciembre de 1946. Disponible en: http://www.suin-juriscol.gov.co/clp/contenidos. dl1/Leyes/1609768?fn=document-frame.htm $\$ \mathrm{f}=$ templates $\$ 3.0$

\section{Jurisprudencia internacional}

Estados Unidos, Corte Suprema de Justicia, Ex parte Milligan 71 US (4 Wall.) 22 (1866). Disponible en: https://supreme.justia.com/cases/federal/us/71/2/case.html http:// www.constitution.org/ussc/071-002a.htm

\section{Jurisprudencia colombiana}

Colombia, Corte Constitucional, Sentencia C-1172-04, 23 de noviembre de 2004, magistrada ponente Clara Inés Vargas-Hernández. Disponible en: http://www. corteconstitucional.gov.co/relatoria/2004/C-1172-04.htm

Colombia, Corte Suprema de Justicia, Sentencia de 21 de noviembre de 1912, magistrado ponente Bartolomé Rodríguez, Gaceta Judicial, Tomo 22 (1913-1914), 1091-1146. Disponible en: http://190.24.134.101/corte/wp-content/uploads/subpage/GJ/ Gaceta\%20Judicial/GJ\%20XXII\%20n.\%C2\%B0\%201091-1146\%20(1913-1914).pdf

Colombia, Corte Suprema de Justicia, Sentencia de 4 de noviembre de 1927, magistrado ponente Luis Felipe Rosales, Gaceta Judicial, 3 de febrero de 1928, Tomo 34 (1929), 1761-1762. Disponible en: http://190.24.134.101/corte/wp-content/uploads/ subpage/GJ/Gaceta $\% 20 J u d i c i a l / G J \% 20 X X X I V \% 20$ n.\%C2\%B0\%201747-1798\%20 (1927-1929).pdf

Colombia, Corte Suprema de Justicia, Sentencia de 10 de agosto de 1954, magistrado ponente Néstor Pineda, abril de 1954, Gaceta Judicial, Tomo 77 (1954-1955), 2140. Disponible en: http://190.24.134.101/corte/wp-content/uploads/subpage/ GJ/Gaceta\%20Judicial/GJ\%20LXXVII\%20n.\%C2\%B0\%202138-2143\%20(19541955).pdf

Colombia, Corte Suprema de Justicia, Sentencia 20, 5 de marzo de 1987, magistrado ponente Jesús Vallejo-Mejía, 2340 Gaceta Judicial, 212-224, enero a junio de 1987. http://190.24.134.101/corte/wp-content/uploads/subpage/GJ/Gaceta\%20Judicial/ GJ\%20CXCI $\% 20$ n. $\%$ C2\%BA $\% 202340 \% 20(1987) \% 20$ Primer $\% 20$ Semestre.pdf

Colombia, Corte Suprema de Justicia, Sentencia 5, 1 de febrero de 1990, magistrados ponentes Hernando Gómez-Otálora y Jaime Sanín-Greiffenstein, Gaceta Judicial, Tomo 201, primer semestre de 1990, 2440. Disponible en: http://190.24.134.101/ corte/wp-content/uploads/subpage/GJ/Gaceta $\% 20 J u d i c i a l / G J \% 20 C C I \% 20$ n. $\%$ C2\%BA $\% 202440 \% 20(1990)$.pdf 